\title{
Activity of Somatosensory-Responsive Neurons in High Subdivisions of SI Cortex during Locomotion
}

\author{
Oleg V. Favorov, ${ }^{1}$ Wijitha U. Nilaweera, ${ }^{2,3}$ Alexandre A. Miasnikov, ${ }^{4}$ and Irina N. Beloozerova ${ }^{2}$ \\ ${ }^{1}$ Department of Biomedical Engineering, University of North Carolina, Chapel Hill, North Carolina 27599, ${ }^{2}$ Barrow Neurological Institute, Phoenix, Arizona \\ $85258,{ }^{3}$ Arizona State University-Barrow Neurological Institute Interdisciplinary Graduate Program in Neuroscience, Tempe, Arizona 85281, and \\ ${ }^{4}$ Department of Neurobiology and Behavior, Francisco J. Ayala School of Biological Sciences, University of California Irvine, Irvine, California 92697
}

\begin{abstract}
Responses of neurons in the primary somatosensory cortex during movements are poorly understood, even during such simple tasks as walking on a flat surface. In this study, we analyzed spike discharges of neurons in the rostral bank of the ansate sulcus (areas 1-2) in 2 cats while the cats walked on a flat surface or on a horizontal ladder, a complex task requiring accurate stepping. All neurons $(n=82)$ that had receptive fields (RFs) on the contralateral forelimb exhibited frequency modulation of their activity that was phase locked to the stride cycle during simple locomotion. Neurons with proximal RFs (upper arm/shoulder) and pyramidal tract-projecting neurons (PTNs) with fast-conducting axons tended to fire at peak rates in the middle of the swing phase, whereas neurons with RFs on the distal limb (wrist/paw) and slow-conducting PTNs typically showed peak firing at the transition between swing and stance phases. Eleven of 12 neurons with tactile RFs on the volar forepaw began firing toward the end of swing, with peak activity occurring at the moment of foot contact with floor, thereby preceding the evoked sensory volley from touch receptors. Requirement to step accurately on the ladder affected $91 \%$ of the neurons, suggesting their involvement in control of accuracy of stepping. During both tasks, neurons exhibited a wide variety of spike distributions within the stride cycle, suggesting that, during either simple or ladder locomotion, they represent the cycling somatosensory events in their activity both predictively before and reflectively after these events take place.
\end{abstract}

Key words: area 1; area 2; cat; neural coding; proprioception; tactile

\section{Introduction}

The primary somatosensory cortical area (SI), comprising cytoarchitectonic areas $3 \mathrm{a}, 3 \mathrm{~b}, 1$, and 2 , is structurally and functionally a heterogeneous cortical region. Although neurons in area $3 \mathrm{~b}$ possess receptive fields (RFs) closely resembling those of the thalamic neurons, neurons in area 1 and especially in area 2, which receive their major input from area $3 b$, possess larger RFs and exhibit greater selectivity for higher-order stimulus features (Iwamura, 1998). This indicates that areas 1 and 2 occupy hierarchically high levels in cortical processing of somatosensory information (Felleman and Van Essen, 1991). It was shown previously that neurons in area 2 are involved in haptic perception during object manipulation (Koch and Fuster, 1989; Iwamura, 1998; Gardner et al., 2007); however, due to technical difficulties in monitoring and controlling spatiotemporal patterns of physical interactions between the hand and manipulated

\footnotetext{
Received Aug. 23, 2014; revised March 14, 2015; accepted April 7, 2015.

Author contributions: 0.V.F., W.U.N., and I.N.B. designed research; O.V.F., W.U.N., and I.N.B. performed research; O.V.F., W.U.N., A.A.M., and I.N.B. analyzed data; O.V.F., W.U.N., and I.N.B. wrote the paper.

This work was supported by the National Institutes of Health (Grant R21 NS-078619 to 0.V.F. and Grant R01 NS-058659 to I.N.B.) and the Arizona State University-Barrow Neurological Institute Interdisciplinary Graduate Program in Neuroscience (W.U.N.). We thank Boris Prilutsky for providing the data on ground reaction forces during walking that are shown in Figure 10A.

The authors declare no competing financial interests.

Correspondence should be addressed to Irina Beloozerova, Barrow Neurological Institute, St. Joseph's Hospital and Medical Center, 350 West Thomas Rd, Phoenix, AZ 85258. E-mail: Irina.Beloozerova@thebni.org.

DOI:10.1523/JNEUROSCI.3545-14.2015

Copyright $\odot 2015$ the authors $\quad 0270-6474 / 15 / 357763-14 \$ 15.00 / 0$
}

objects, the nature of information-processing tasks performed by area 2 neurons, their contribution to perception, or even most basically the somatosensory representation of events by these neurons remain essentially unknown.

Locomotion is a behaviorally prevalent form of object-body interactions. During routine locomotion, a regularly repeating pattern of proprioceptive input to SI is periodically supplemented by tactile input coming from skin areas of the volar feet. It is believed that this tactile input enables perception of the properties of the walking surface. The study by Fitzsimmons and colleagues (2009) in rhesus macaques walking with their hind limbs on a treadmill showed that information about foot contact with the ground can be readily extracted from spike-firing patterns of 40-150 neurons simultaneously recorded in SI areas 1-2, along with information about speed of walking; step length; positions and angles of the hip, knee, and ankle joints; and leg muscle contractions. In sitting monkeys, however, it appears that, in addition to the somatosensory information, SI receives efference copy signals from the motor system. The major evidence for this is the fact that many SI neurons raise their spike discharge activity up to few hundreds of milliseconds before the onset of an actively generated limb movement, preceding even EMG activity (Soso and Fetz, 1980; Nelson, 1987; Lebedev et al., 1994; London and Miller, 2013). Furthermore, in the vibrissae system, it was shown that both the somatosensory and efference copy signals contribute to activation of neurons in the SI during whisking (Fee et al., 1997; Kleinfeld and Deschênes, 2011). However, because of the 
difficulties associated with obtaining stable single neuron recording in walking subjects, with the exception of the study of Fitzsimmons and colleagues (2009) in rhesus macaques and a few studies in rats (Chapin and Woodward, 1982a,1982b), which investigated treadmill locomotion, little is known about what takes place in SI during walking.

Here, we have analyzed spiking activity of 82 neurons from the forelimb representations of two cats that walked in an experimental chamber on a flat surface or on crosspieces of a horizontal ladder, a task that required accurate placing of paws. A brief account of this study was published previously in abstract form (Favorov et al., 2010).

\section{Materials and Methods}

Experiments. Extracellular recordings from single neurons in areas 1 and 2 of the SI cortex were obtained during chronic experiments in cats. Two adult females were used. Methods of surgical preparation and recording technique have been described previously in detail (Prilutsky et al., 2005; Stout and Beloozerova, 2013) and will be reported only briefly here. All experiments were conducted at the Barrow Neurological Institute. The experimental protocol was in compliance with the National Institutes of Health's Guidelines for the Care and Use of Laboratory Animals and was approved by the Barrow Neurological Institute Animal Care and Use Committee.

Locomotor tasks. Two locomotor tasks were used: walking on a flat surface and walking on crosspieces of a horizontal ladder (see Fig. 1A, $B$ ). Biomechanics and limb muscle activities in the cat during walking on the flat surface and on the horizontal ladder in a similar experimental setup have been described previously in detail (Beloozerova et al., 2010). It was shown that walking along the ladder is similar to walking on the flat surface in nearly all kinematic and EMG parameters tested except that the variability of stride lengths is much smaller during ladder walking because ladders' crosspieces narrowly determine where the cat steps. It was shown in several studies that, whereas walking on the flat surface does not require vision and can be accomplished without the forebrain, walking on a ladder relies on vision and requires thalamocortical processing to be successful (Trendelenburg, 1911; Liddell and Phillips, 1944; Chambers and Liu, 1957; Beloozerova and Sirota, 1993, 2003; Sherk and Fowler, 2001; Metz and Whishaw, 2002; Friel et al., 2007; Marigold and Patla, 2008; Rivers et al., 2014).

Cats were trained to walk in an experimental chamber over a period of 1 month (Skinner, 1938; Pryor, 1975). Positive reinforcement by food was used. The walking chamber was a rectangular enclosure with 2 connected parallel corridors $(2.5 \times 0.3 \mathrm{~m}$ each $)$ similar to that used in a number of our previous studies (Beloozerova and Sirota, 2003, Sirota et al., 2005; Beloozerova et al., 2010; Stout and Beloozerova, 2013). In one corridor, the walking surface was flat, whereas the other corridor contained a horizontal ladder. The centers of the ladder crosspieces were spaced $25 \mathrm{~cm}$ apart, equal to $1 / 2$ of a cat's average stride length during locomotion in the chamber with flat floor (Beloozerova and Sirota, 1993, Beloozerova et al., 2010). The crosspieces had flat tops and were $5 \mathrm{~cm}$ wide, which was slightly greater than the 3 -cm-diameter support area of the cat foot. Cats always stepped on the middle of the crosspiece and thus had full support for their paws. The ladder was elevated above the chamber's floor by $6 \mathrm{~cm}$. While walking in the chamber, cats passed through the two corridors sequentially, occasionally changing direction from clockwise to counterclockwise. After each round, food was dispensed into a feeding dish in one of the corners. Cats were trained, upon arrival, to stand quietly in front of the feeding dish for 3-5 s. During data analysis, $1 \mathrm{~s}$ in the middle of this period was considered as "standing." Cats continued walking until a sufficient number of steps for each locomotor task was recorded.

Cats were accustomed to wearing a cotton jacket, a light backpack with connectors, and a sock with a small metal plate on the sole of the foot for recording foot contact with the floor. The floor in the chamber and the crosspieces of the ladder were covered with an electrically conductive rubberized material. During locomotion, the duration of the swing and stance phases of the forelimb contralateral to the side of recording in the
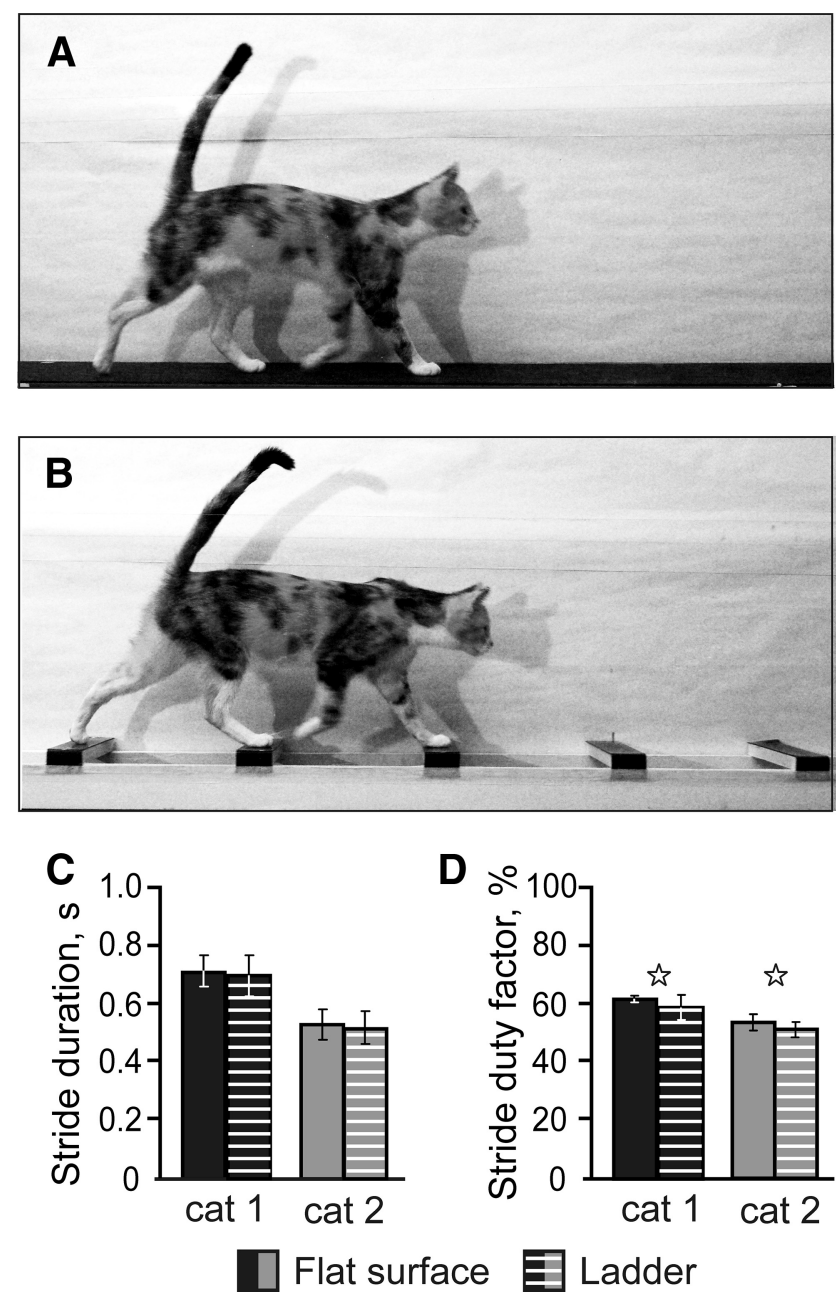

Figure 1. Locomotor tasks. The experimental box was divided into two corridors. $A, B$, In one corridor, the floor was flat $(\boldsymbol{A})$, whereas the other corridor contained a horizontal ladder $(\boldsymbol{B}) . \boldsymbol{C}$, Duration of strides during flat surface and ladder walking. $\boldsymbol{D}$, Stride duty factor (proportion of the stance phase in the step cycle) during flat surface and ladder walking. Stars indicate statistically significant difference ( $p<0.05, t$ test).

SI was monitored by measuring the electrical resistance between the plate and the floor (Beloozerova and Sirota, 1993; Stout and Beloozerova, 2013). The cat's passage through the beginning and the end of each corridor was recorded using infrared photodiodes.

Surgical procedures. Surgery was performed under isoflurane anesthesia in aseptic conditions. The skin and fascia were retracted from the dorsal surface of the skull. At 10 points around the circumference of the skull, stainless steel screws were implanted. The screw heads were then embedded into a plastic cast that formed a circular base. Later, this base was used for fixation of connectors, electrode microdrive, and preamplifier and to hold the cat's head rigidly while searching for neurons. On the left side of the head, the dorsal surface of the sigmoid gyrus was exposed by removal of $\sim 1.6 \mathrm{~cm}^{2}$ of bone and dura mater. The region of the SI cortex was visually identified based on surface features and photographed (Fig. $2 A, B$ ). The exposure was covered with a 1 -mm-thick acrylic plate. The plate was pre-perforated with holes $0.36 \mathrm{~mm}$ in diameter spaced by $0.5 \mathrm{~mm}$ and the holes were filled with bone wax. The plate was fixed to the surrounding bone by orthodontic resin (Dentsply Caulk). This allowed for later insertion of recording electrodes in the SI cortex. In addition, 226 gauge hypodermic guide tubes were implanted vertically above the medullary pyramids with tips approximately at the Horsley-Clarke coordinates (P7.5, L0.5) and (P7.5, L1.5), and a depth of H0. They were later used for physiologically guided insertion of stimulating electrodes into the pyramidal tract (Prilutsky et al., 

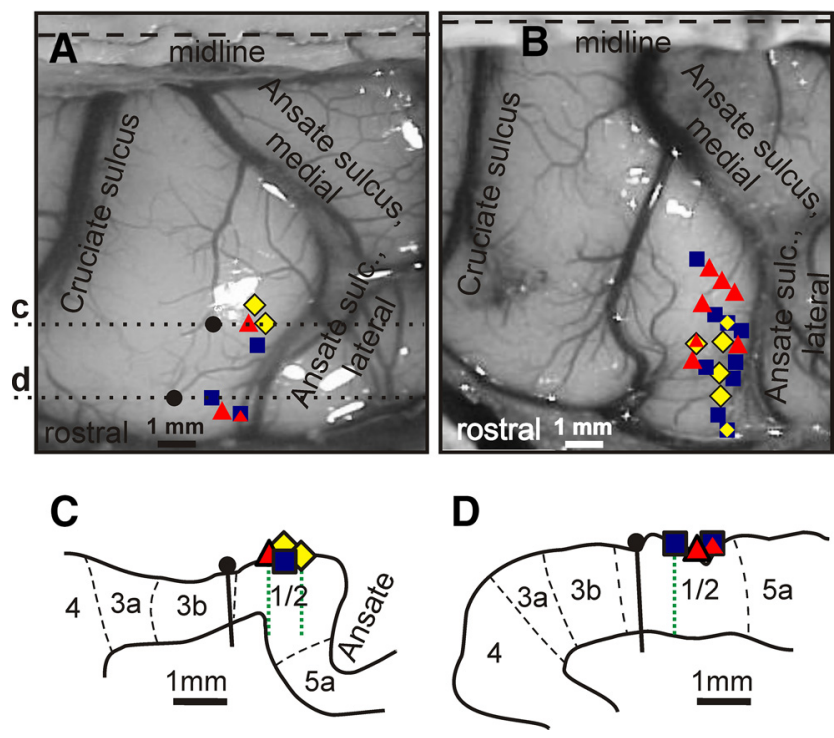

Figure 2. Location of neurons. $A, B$, Areas of recording in the forelimb representation of the left Sl in cats $1(\boldsymbol{A})$ and cat $2(\boldsymbol{B})$. Microelectrode entry points into the cortex are shown by colored symbols. Q Penetrations where the majority of recorded neurons had RFs on the shoulder, arm, and/or forearm and were not responsive to stimulation of the wrist or paw; $\downarrow$, penetrations where most recorded neurons had RFs on the arm and/or forearm and also responded to stimulation of the wrist and/or paw; $\boldsymbol{\Lambda}$, penetrations where most neurons had RFs on the wrist and/or paw. Symbols with combined colors indicate points where approximately equal number of neurons with different RFs were found. In $A$, black circles show locations of reference lesions and dotted lines $\boldsymbol{c}$ and $\boldsymbol{d}$ indicate positions of parasagittal sections, schematics of which are shown in fragments $\boldsymbol{C}$ and $\boldsymbol{D}$. $\boldsymbol{C}, \boldsymbol{D}$, Outlines of cortical gray matter of two parasagittal sections of cat 1 cortex with borders between cytoarhitectonic areas indicated by dashed lines. Locations of microelectrode entry points are shown with the same symbols as in $\boldsymbol{A}$ and $\boldsymbol{B}$. Reference lesions are shown with black circles and vertical black bars and microelectrode tracks are shown with dotted green lines.

2005). These electrodes were used for identification of pyramidal tract neurons (PTNs) in the awake animal. Immediately after the surgery and then $12 \mathrm{~h}$ thereafter, the analgesic buprenorphine was administered intramuscularly.

Single-unit recording. Several days after the surgery, the cat was placed on a table equipped with a comforting pad and encouraged to take a "sphinx" posture. After the cat rested in this posture for several minutes, the base attached to the skull during surgery was fastened to an external frame so that the resting position of the head was approximated. This procedure minimized stress on the neck while the head was immobilized. After a few training sessions, both cats sat quietly with their head restrained. They did not seem to be disturbed by the restraint and frequently fell asleep.

Extracellular recordings from the rostral bank of the lateral ansate sulcus were obtained using tungsten varnish-insulated microelectrodes (120 $\mu \mathrm{m}$ in outer diameter; FHC). The impedance of electrodes was 1-3 $\mathrm{M} \Omega$ at $1000 \mathrm{~Hz}$. A custom-made, lightweight $(2.5 \mathrm{~g})$ manual single-axis micromanipulator chronically mounted on the cat's skull was used to advance the microelectrode. Signals from the microelectrode were preamplified with a miniature, custom-made preamplifier positioned on the cat's head and then further amplified and filtered $(0.3-10 \mathrm{kHz}$ bandpass) with the CyberAmp 380 (Molecular Devices). After amplification, signals were digitized with a sampling frequency of $30 \mathrm{kHz}$ and recorded using a computerized data acquisition package (Power-1401/Spike-2 System; Cambridge Electronic Design). An example of a raw recording from a neuron during locomotion is shown in Figure $4 A$.

Identification of neurons and classification of their RFs. Waveform analysis was used to discriminate and identify the spikes of individual neurons using the Power-1401/Spike-2 system waveform-matching algorithm. Only the neurons with stable spike shape were used for analysis. In addition, all neurons were tested for antidromic activation from the pyramidal tract, which was stimulated with $0.2 \mathrm{~ms}$ rectangular pulses of
0.1-1.0 mA current. These pulses typically did not evoke any visible motor responses and never produced any signs of discomfort or distress in the cats. The principal criterion for identification of antidromic activation of PTNs was the test for collision of spikes (Bishop et al., 1962; Fuller and Schlag, 1976). A stable response latency and consistent collision were required for neurons to be classified as PTNs. For calculation of the conduction velocity, the distance between recording electrodes in the SI and stimulation electrodes in the pyramidal tract was estimated as 50 $\mathrm{mm}$. This calculation accounted for the curvature of the pathway and also for the spread of the current and refractory period at the site of stimulation.

The somatic RFs of neurons were examined in animals resting with their heads restrained. Somatosensory stimulation was produced by lightly stroking fur, tapping the skin with von Frey filaments, palpating muscle bellies and tendons, and by passive joint movements. The spatial extent of an RF was determined by identifying the entire area from which action potentials could be elicited by the most effective mode of stimulation.

Locomotion data analysis. From each walk down the corridor, two or three strides made in the middle of the walkway were selected for the analysis. It was shown previously that the strides in the middle of the corridor are normally made at a nearly constant speed with no net acceleration or deceleration and that their average stride length during flat surface and ladder locomotion is identical (Beloozerova et al., 2010). To compare the activity of neurons during two locomotor tasks, we used only the strides for which the average duration in the two tasks differed by $<10 \%$.

The onset of swing of the right forelimb (contralateral to the SI recording site) was taken as the beginning of the step cycle. The duration of each step cycle was divided into 20 equal bins and a phase histogram of the discharge rate of the neuron in the cycle was generated and averaged over all selected cycles. The phase histograms were smoothed by recalculating the value of each bin as follows: $\hat{F}_{i}=0.25 F_{i-1}+0.5 F_{i}+0.25 F_{i+1}$, where $F i$ is the original value of bin $i$. The first bin was considered to follow the last one; the last bin was considered to precede the first one. The stride-to-stride variability of the mean discharge rate of individual neurons was calculated as the variance-to-mean ratio, where $V M R=$ $(\mathrm{SD})^{2} /($ mean rate over the stride cycle), commonly also called the Fano factor. The "depth" of modulation $(d M)$ was calculated using the histogram. It was defined as $d M=\left[\left(N_{\max }-N_{\min }\right) / N\right] \times 100 \%$, where $N_{\max }$ and $N_{\min }$ are the number of spikes in the maximal and the minimal histogram bin, respectively, and $N$ is the total number of spikes in the histogram. Neurons with $d M>4 \%$ were judged to be stride related. This criterion was adopted from the motor cortex, where it was determined using an analysis of fluctuations in the activity of neurons in the resting animal (Efron and Tibshirani, 1993; Stout and Beloozerova, 2013). In stride-modulated neurons, the portion of the cycle in which the activity level exceeded $25 \%$ of the difference between the maximal and minimal frequencies in the histogram was defined as a "period of elevated firing" (PEF) (as illustrated in Fig. 4C,E). PEFs were smoothed by renouncing all 1 -bin peaks and troughs (a total of $0.6 \%$ of bins were altered throughout the database). In addition, in neurons with a single PEF, the "preferred phase" of discharge was assessed using circular statistics (Batshelet, 1981; Drew and Doucet, 1991; Fisher, 1993; Beloozerova et al., 2003a; Sirota et al., 2005). For this purpose, the occurrence of each spike was treated as a vector of a unit length and the preferred phase was calculated as the phase of the mean vector.

The effects of locomotor task on parameters of strides, discharge rate of individual neurons, and mean parameters of group activities of neurons were tested using two-tailed Student's $t$ test. When comparing the $d M$ of individual neurons, their preferred phases of activity, and duration of PEF during the 2 walking tasks, differences $\geq \pm 2 \%$, $\pm 10 \%$, and $\pm 20 \%$, respectively, were considered significant. These criteria were adopted from the motor cortex, where they were established based on the results of a bootstrapping analysis (Efron and Tibshirani, 1993) that compared differences in discharges between various reshufflings of strides of the same locomotor task (Stout and Beloozerova, 2013).

A nonparametric $\chi^{2}$ test or $t$ test for proportions were used for comparison of categorical data. For all tests, the significance level was set at 
$p=0.05$. Unless indicated otherwise, for all mean values, the SEM is given.

Histological procedures. At the termination of experiments, cats were deeply anesthetized with sodium pentobarbital. Several reference lesions were made in the region of the cortex from which neurons were sampled. Cats were then perfused with isotonic saline followed by a $4 \%$ formaldehyde solution. The studied cortical region and the hindbrain containing the pyramidal tract were frozen and sectioned serially at $50 \mu \mathrm{m}$. The sections were stained for Nissl substance with cresyl violet. The position of stimulation electrodes in the medullar pyramids was verified. The positions of recording tracks in the cortex were estimated in relation to the reference lesions and with regard to cytoarchitectonic boundaries separating areas $3 \mathrm{~b}, 1,2$, and $5 \mathrm{a}$ (identified by criteria of Hassler and Muhs-Clement, 1964; Dykes et al., 1980; McKenna et al., 1981; Fig. 2). Namely, in parasagittal sections of the lateral portion of the posterior sigmoid gyrus, moving in the rostrocaudal direction, one can recognize sequentially areas $3 b, 1$, and 2 . In area $3 b$, granular layer IV is readily detected as having a thick band of small, densely packed cells bounded below by cell-poor layer $\mathrm{V}$ and above by sublayer IIIc containing darkly stained pyramidal cells (Leclerc et al., 1994; Ito and Craig, 2003). Area 1 is characterized by a clear laminar arrangement and a radial appearance involving all laminae (Ghosh, 1997a) and the presence of large pyramidal cells in widened layer $\mathrm{V}$ (Leclerc et al., 1994). In the forelimb area, a clear-cut boundary between areas 1 and 2 could be determined reliably (McKenna et al., 1981). Area 2 usually occupies most of the rostral wall of the lateral ansate. It possesses a thick layer I, wide laminae IIIc and V, many large pyramidal cells in layer Vb (Ghosh, 1997a), and gradually declining width of layer VI. In the lateral ansate, it extends toward the fundus of the sulcus, where it borders area $5 \mathrm{a}$. In area 5, laminae III and V are narrower and lamina IV is well defined (Ghosh, 1997a; Andujar and Drew, 2007). The overall area pattern over the flattened (planar reconstruction of) hemisphere was most recently reported in general by Clasca et al. (2000) and in greater detail by Andujar and Drew (2007).

\section{Results}

\section{Population studied}

This report describes activity of 82 neurons recorded in the rostral bank of the lateral ansate sulcus that had RFs on the contralateral forelimb. Figure 2, $A$ and $B$, shows the entry points of microelectrode penetrations in which neurons were collected in cat 1 ( 25 neurons; Fig. 2A) and cat 2 (57 neurons; Fig. 2B). Histological examination showed that all electrode tracks were confined to the cytoarchitectonic areas 1 and 2 (Fig. 2C,D). All of the neurons studied were active while the cat was standing, awaiting reward after each trip around the chamber. The mean discharge rate varied from 0.5 to 50 spikes/s. The size of the RF varied from about $2 \mathrm{~cm}^{2}$ to as large as nearly the entire lateral or medial aspect of the limb (Fig. 3).

\section{Characteristics of locomotion}

During recording of each neuron, cats walked between 10 and 50 (typically 20-30) times down each of the chamber's corridors $(25 \pm 8$, mean $\pm \mathrm{SD})$. The number of strides selected for the analysis according to the criteria described in the Materials and $0.05, t$ test).

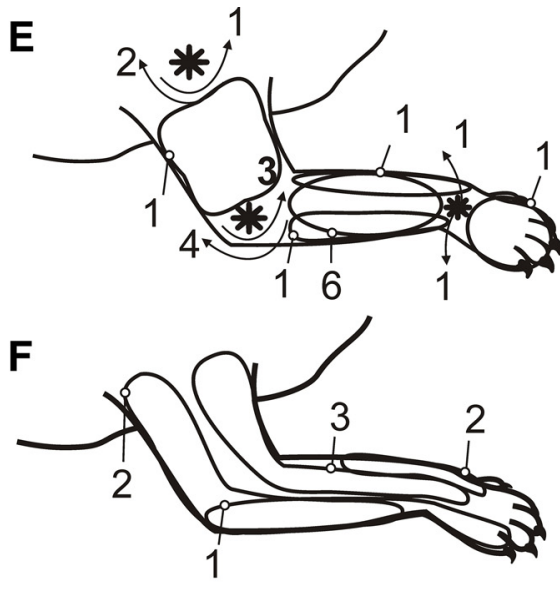

G

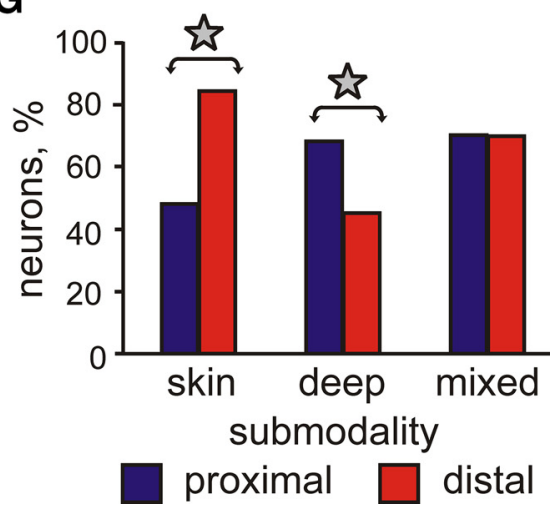

Figure 3. RFs of neurons. In $\boldsymbol{A}-\boldsymbol{F}$, outlines show locations of RFs of individual neurons on the forelimb. Numbers indicate the direction of the joint movement to which the cells responded. G, Proportions of neurons with distal (wrist/paw) versus proximal (upper arm/forearm) RFs among neurons with skin, deep, and mixed RFs. Stars indicate statistically significant difference ( $p<$

Methods section ranged between 20 and $80(45 \pm 15$, mean \pm SD) for both flat surface and ladder walking. For different neurons, the average duration of selected strides was between 450 and $800 \mathrm{~ms}$, which corresponded to the speed of walking of $0.8-1.1$ $\mathrm{m} / \mathrm{s}$. Although cat 2 walked faster than cat 1 , for each cat, the average duration of the strides during the 2 tasks was the same $(p>0.05, t$ test; Fig. $1 C)$. The ratio of stance duration to the duration of the cycle (the stride duty factor) was $0.45-0.64$. In both cats, the duty factor was smaller during the ladder task $(p<$ $0.05, t$ test), but the difference was small ( $4-5 \%$; Fig. $1 D)$. The gait that cats used during locomotion was a walk with the support formula of 2-3-2-3-2-3-2-3, which indicates the number of limbs supporting the body during different phases of the stride cycle (Hildebrand, 1965).

\section{Example firing behavior of a neuron during standing and walking}

An example of a neuron's spiking activity during standing, walking on the flat surface, and along the ladder is shown in Figure 4. This fast-conducting PTN had a slowly adapting cutaneous RF covering the glabrous skin of the entire central pad, which should be fully in contact with the ground and thus well stimulated when the cat was standing. Nevertheless, this neuron had low spike firing activity while standing $(6.3$ spikes/s; marked by a dashed horizontal line in Fig. 4C,E).

During locomotion, the neuron's average activity rose substantially to $18.8 \mathrm{spikes/s}$ on the flat surface and $18.2 \mathrm{spikes} / \mathrm{s}$ on 


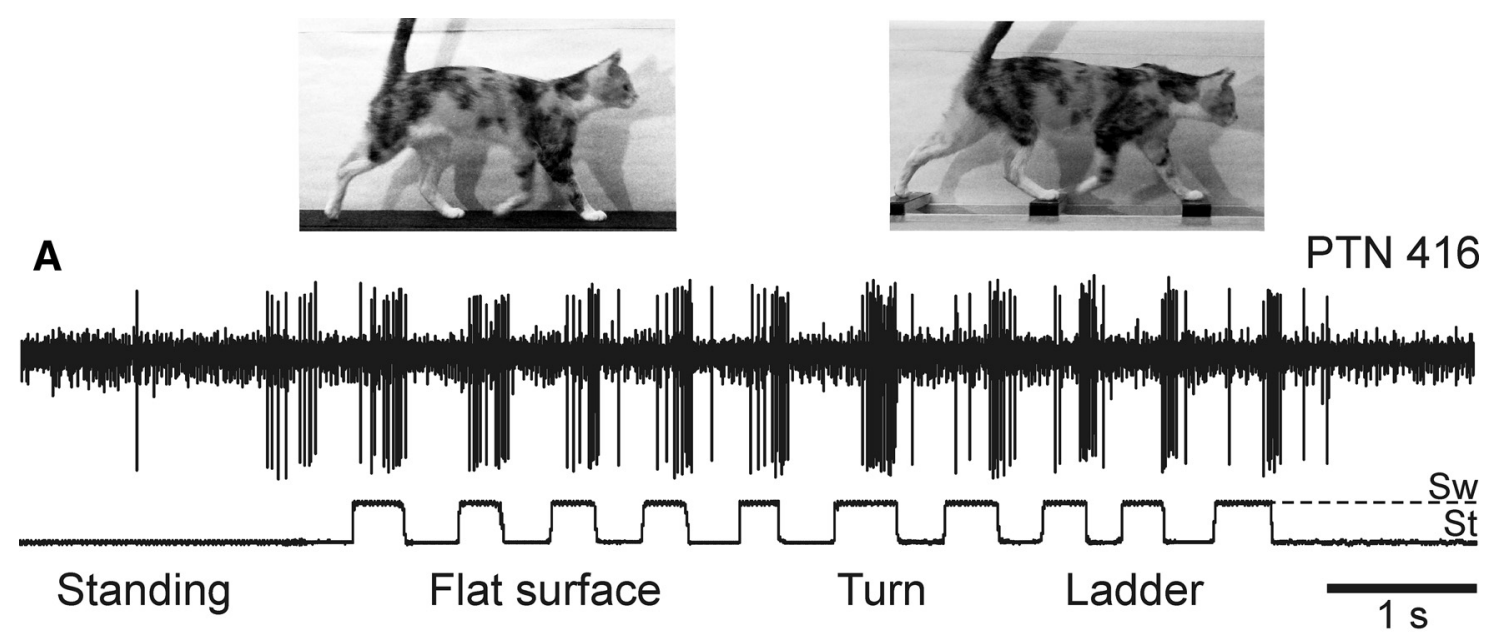

B

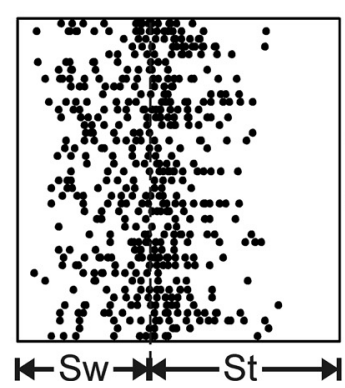

C

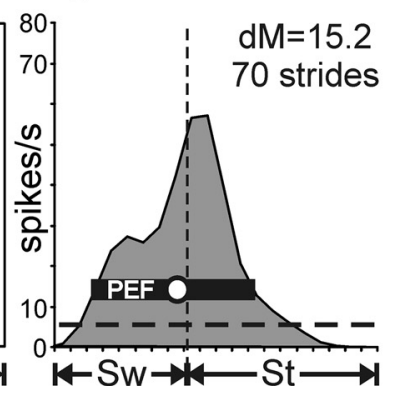

D

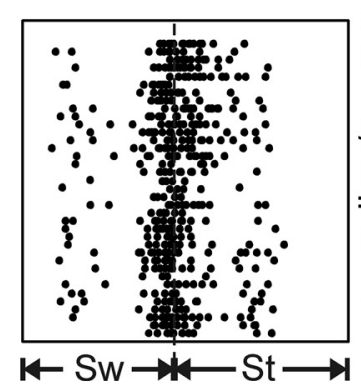

E

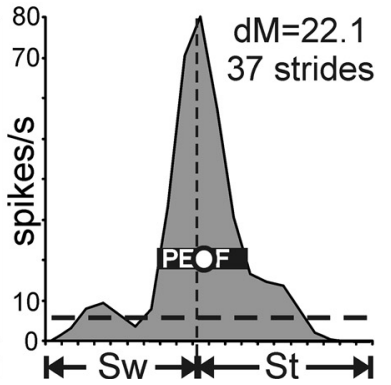

Figure 4. Exemplary activity of a neuron during standing and walking on the flat surface and horizontal ladder. A, Activity of PTN 416 during standing and walking. The bottom trace shows the swing (Sw) and stance (St) phases of the step cycle of the right forelimb that is contralateral to the recording site in the cortex. B, C, Activity of the same neuron during flat surface locomotion is presented as a raster of 40 step cycles $(\boldsymbol{B})$ and as a histogram of 70 step cycles $(\boldsymbol{C})$. In the rasters, spike occurrences are indicated with dots. In the raster and histogram, the duration of step cycles is normalized to $100 \%$ and, in the histogram, the interrupted horizontal line shows the level of activity during standing. The horizontal black bar shows the PEF and the circle indicates the preferred phase as defined in the Materials and Methods. $\boldsymbol{D}, \boldsymbol{E}$, Activity of the same neuron during ladder locomotion presented as a raster $(\boldsymbol{D})$ and as a histogram $(\boldsymbol{E})$ of 37 step cycles. In $\boldsymbol{B}-\boldsymbol{E}$, vertical interrupted lines indicate the end of stance and the beginning of the swing phase.

the ladder. Moreover, the firing rate of the neuron was prominently modulated with respect to the step cycle. The neuron was active during most of the swing phase and the first half of the stance phase, reaching a peak rate of 57 spikes/s at the beginning of stance when walking on the flat surface, and was less active during the end of the stance and early swing phases. During walking along the ladder, the neuron's firing activity was even more strongly modulated. The neuron became still more active during transition from swing to stance, now reaching discharge frequency of 80 spikes/s, whereas its activity during the first half of the swing phase decreased.

The rasters in Figure $4, B$ and $D$, show the activity of the neuron across 40 individual strides during flat surface walking (Fig. 4B) and 37 strides during ladder walking (Fig. 4D). The pattern of activity was very consistent across strides of each locomotor task. The activity is summed in Figure 4, $C$ and $E$, which shows a histogram of the neuron's firing rate across the step cycle during flat surface (Fig. 4C) and ladder (Fig. 4E) walking. The $\mathrm{PEF}$ is indicated by a black horizontal bar; it spanned most of the swing phase and the first third of the stance phase during flat surface walking, but was confined to the swing-to-stance transition phase and was only half as long during walking along the ladder. The preferred phase (indicated by a circle in Fig. 4C,E) was at the very end of the swing phase during flat surface walking and at the very beginning of the stance phase during ladder walking.
Effect of locomotion on mean spike discharge rates

When the cat was standing in front of the feeding dish after each trip around the chamber, the mean discharge rate of neurons was $13.3 \pm 1.2$ spikes/s. The activity of neurons with RFs confined to the wrist and paw was lower than that of cells with more proximal RFs ( $11.7 \pm 1.3$ vs $17.4 \pm 2.5$ spikes $/ s, p<0.05, t$ test $)$. The mean discharge rate of neurons with skin and deep RFs, however, was similar, as was the mean firing rate of fast- and slow-conducting PTNs $(p>0.05, t$ test $)$.

When the cat was walking on the flat surface, the mean activity of the entire population of neurons was similar to that during standing $(16.6 \pm 1.4$ vs $13.3 \pm 1.2$ spikes/s, $p>0.05, t$ test $)$. However, locomotion had diverse statistically significant effects on the mean discharge rates of individual neurons and groups of neurons. During locomotion, 44\% (36/82) of cells increased their mean discharge rate, on average by 3 -fold, whereas $22 \%(18 / 82)$ decreased it by as much as $80 \%$ compared with standing (Fig. $5 A$ ). The majority of neurons with RFs on the wrist and/or paw increased the discharge rate and this group's average rate during walking was higher than during standing by 9.3 spikes/s. In contrast, neurons with RFs on the upper arm or forearm discharged with similar mean rates during standing and walking. PTNs, both fast- and slow-conducting, more often changed their discharge rate with the start of locomotion than the rest of the population ( $p<0.05, t$ test) and typically increased rather than decreased it. Neurons with deep RFs tended to be more active during walking 

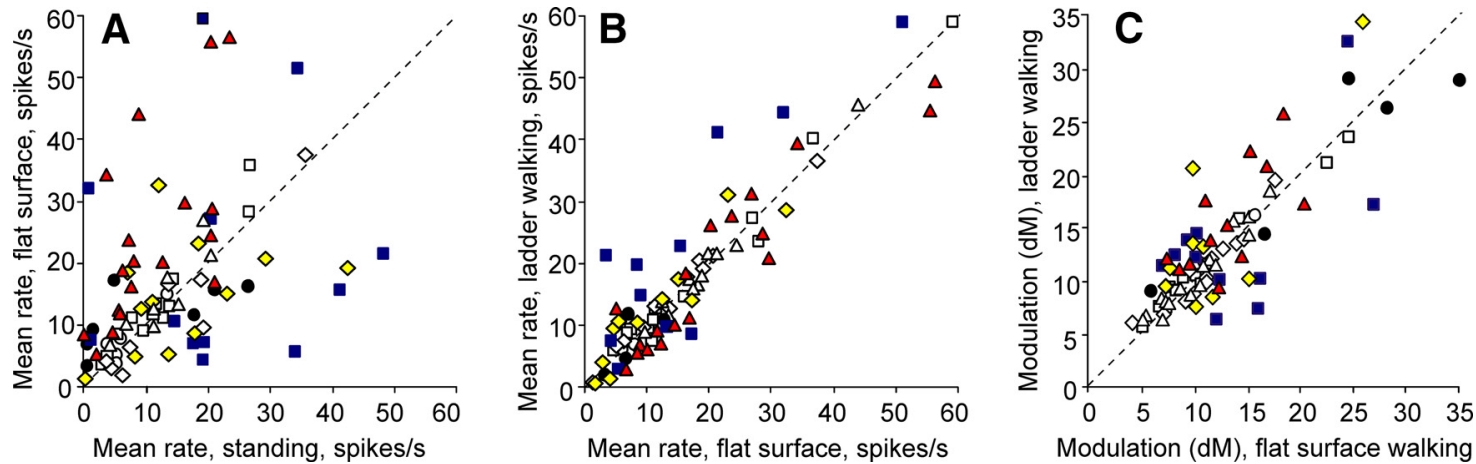

Figure 5. Comparison of activity characteristics of individual neurons between different tasks. $A$, Mean discharge frequency averaged over all selected strides of flat surface walking is plotted against the mean frequency observed during standing. $\boldsymbol{B}$, Mean discharge frequency averaged over all selected strides of walking along the ladder is plotted against that of flat surface walking. $\boldsymbol{C}$, Mean depth of frequency modulation during walking along the ladder is plotted against that of flat surface walking. In $\boldsymbol{A}-\boldsymbol{C}$, the abscissa of each point shows the values observed during one task and ordinate shows values seen during the other task. Differently shaped symbols represent neurons with RFs on different segments of the forelimb: $\mathbf{\square}$, neurons with RFs on the arm and/or forearm, which did not respond to stimulation of the wrist or paw; $\bullet$, neurons with RFs on the arm and/or forearm that were also responsive to stimulation of the wrist and/or paw; $\boldsymbol{\Lambda}$, neurons with RFs confined to the wrist and/or paw; neurons with an RF that encompassed most of the limb and neurons with incompletely mapped RFs. Neurons with characteristics that were statistically significantly different during the two tasks (see Materials and Methods) are shown with filled symbols.

than those with skin RFs, but the difference did not reach the level of statistical significance $(p=0.068)$. Across all cells, neurons with relatively low activity during standing $(<10$ spikes/s) nearly always increased it with the start of locomotion, whereas more active neurons could either decrease or increase the activity. The stride-to-stride $V M R$ was $1.68 \pm 0.89$ (mean $\pm \mathrm{SD})$.

\section{Stride-synchronized modulation of spike discharges}

During locomotion, the discharge of all 82 neurons was modulated with respect to the stride: it was greater in one phase of the stride and smaller in another phase. There were two major forms of modulation: 78\% (64/82) of cells had one period of elevated firing (PEF, see Methods) per stride and 22\% (18/82) had two PEFs.

Figure 6, $A$ and $B$, shows phase positions within the step cycle of PEFs and preferred phases of all one-PEF neurons. PEFs of different neurons were distributed throughout the cycle. Their duration varied between neurons in the range of $15-90 \%$ of the cycle, and was $52 \pm 2.5 \%$ of the stride time on average. At any given time of the cycle, $40-75 \%$ of the cells were in their PEF (Fig. $6 C)$. However, more neurons had PEFs and preferred phases during late swing or early stance than in the opposite phase (Fig. $6 A-C)$. As a result, the average discharge rate of one-PEF population was peaking at $\sim 25$ spikes/s at the end of swing/beginning of stance phase and decreased in half to about 12 spikes/s during midstance (Fig. $6 D ; p<0.05, t$ test).

Among individual neurons, the magnitude of the striderelated modulation varied. Seventeen percent (14/82) of neurons were completely silent for a part of the step cycle; the majority, however, were active throughout the cycle, whereas their discharge rate was modulated. The average $d M$ across the one-PEF population was $13.3 \pm 6.6($ mean $\pm \mathrm{SD})$.

The activity of a typical neuron with two PEFs per stride is shown in Figure 7A. This neuron had a slowly adapting cutaneous RF on the paw. It was active during the second half of the stance and first half of the swing phase, reaching a frequency of 52 spikes/s at beginning of swing while discharging only around 10-20 spikes/s during midswing and midstance. The neuron's activity, however, was as high as 40 spikes/s during the transition from the swing to stance phases, thus forming the second, albeit shorter, PEF. The magnitude of $d M$ was 9.1. During walking along the ladder, the activity of the neuron became even more strongly modulated $(d M=17.8$; Fig. $7 G, H)$. Although the neuron became less active during its longer PEF, the activity during the shorter PEF increased. In addition, the activity during both inter-PEF intervals further decreased, as much as nearly zero during the late swing phase. The total duration of PEF was smaller on the ladder by $20 \%$ of the stride cycle.

Figure $7 C$ shows phase positions within the step cycle of PEFs of all two-PEF neurons, with PEFs of the example neuron shown on the top of the graph. PEFs of different neurons were distributed throughout the cycle. Their duration varied among neurons in the range of $35-80 \%$ of the cycle and was $57 \pm 4 \%$ of the stride time on average. Thirteen of 18 neurons had PEFs that differed in duration by $10 \%$ or more of the stride cycle: "long" and "short" PEFs. The duration of the long PEF ranged from $20 \%$ to $55 \%$ of the cycle and that of the short PEF was $10-35 \%$. In the activity of all but one of these neurons, the longer PEF was also the stronger one, because the peak discharge rate in it exceeded that in the shorter PEF by $20 \pm 15$ spikes/s. Across the entire two-PEF population, at any given time of the cycle, $45-75 \%$ of the cells were in their PEF (Fig. 7E). As a group, two-PEF neurons had two approximately equal activity peaks: one at the very end of the swing phase, which was similar to the peak of the one-PEF neuronal population, and the other peak near the transition from the stance to swing phase (Fig. $7 F$ ). Among individual neurons, the magnitude of the stride-related modulation varied, with the average $d M=10.1 \pm 0.6$, slightly lower than in the one-PEF group $(p<0.05, t$ test $)$.

\section{Grouping of neurons based on activity position in respect to the swing and stance phases of the stride}

Although the one- and two-REF spike discharge patterns were the most conspicuous features of the discharge frequency modulation during walking, stride activity profiles-the frequency of spike firing as a function of the phase of the stride cycle-also varied greatly among neurons. Activity profiles of all cells could be divided into six groups based on the relationship of their PEFs to the transitions between the swing and stance phases of the stride cycle. In each panel of Figure 8, activity profiles of all cells belonging to a particular group are shown superimposed in a single plot. Neurons in Group 1 ( $32 \%$ of cells) were preferentially active during the swing phase of the stride cycle. Neurons in Group $2(17 \%)$ had their activity centered on the moment of the 


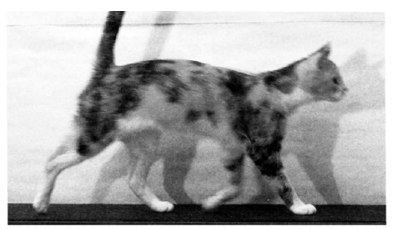

A

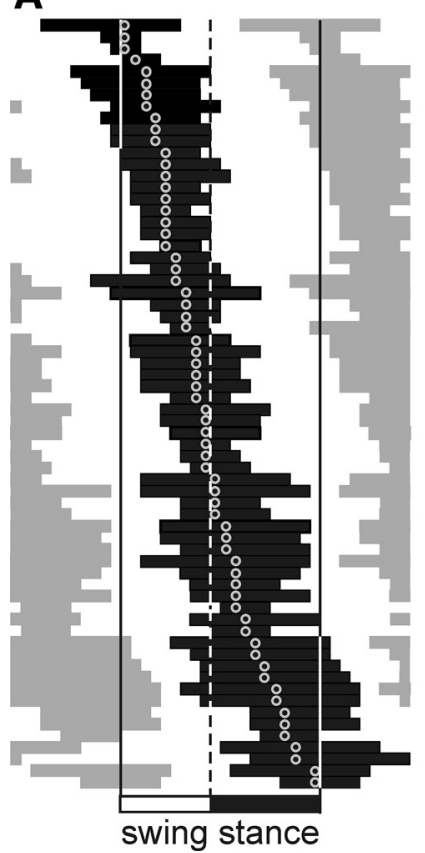

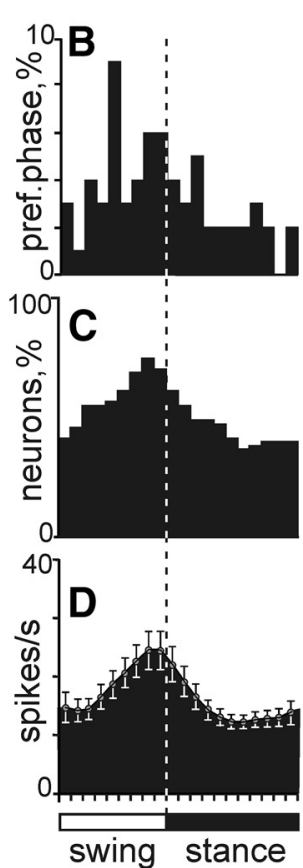

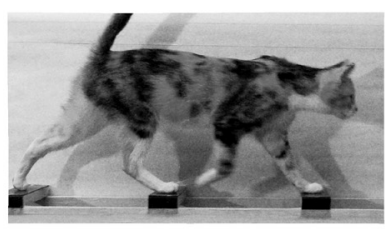

E

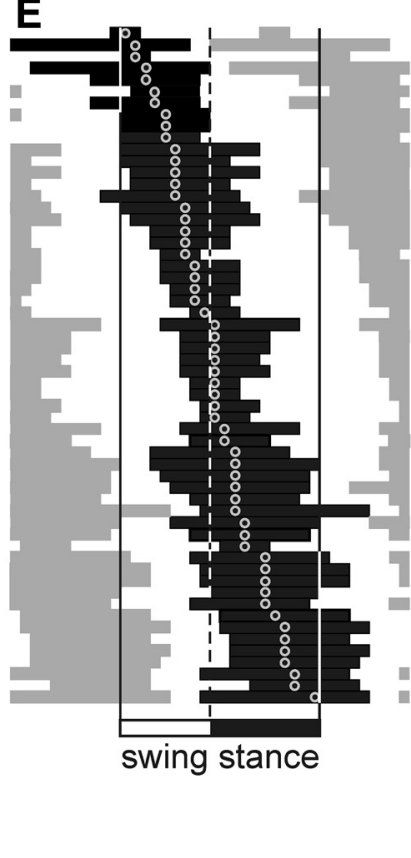

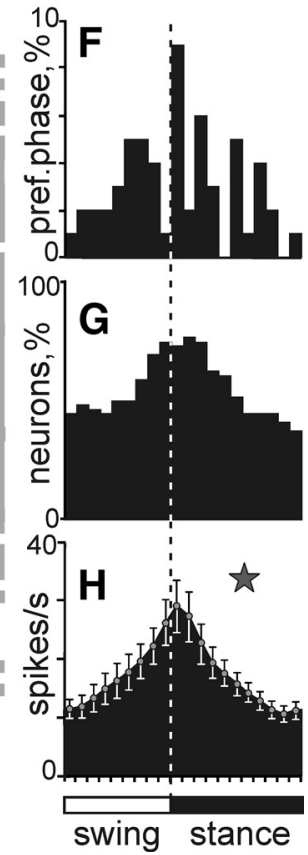

Figure 6. Population characteristics of one-PEF neurons. $\boldsymbol{A}, \boldsymbol{E}$, Phase distribution of PEFs during walking on the flat surface $(\boldsymbol{A})$ and along the ladder ( $\boldsymbol{E})$. Each row represents the PEF of one cell. A circular mark on a PEF denotes the preferred phase. Neurons are rank ordered so that those with a PEF earlier in the cycle are plotted on the top of the graph. The top row shows PEF and preferred phase of the neuron, the activity of which is shown in detail in Figure 4. Vertical interrupted lines indicate the end of stance and the beginning of the swing phase. $\boldsymbol{B}, \boldsymbol{F}$, Distribution of preferred phases. $\boldsymbol{C}, \boldsymbol{G}$, Proportion of active neurons (neurons in their PEF) in different phases of the step cycle. $\boldsymbol{D}, \boldsymbol{H}$, Mean discharge rate at different phases of the step cycle. Error bars show SEM. Star in $\boldsymbol{H}$ indicates the phase during which the activity of neurons during ladder walking is higher than during flat surface walking $(p<0.05, t$ test).

foot contact with the ground. Neurons in Group 3 (18\%) were preferentially active during the stance phase of the stride cycle. Neurons in Group $4(5 \%)$ had their activity peaked around the time the foot broke contact with the ground or, in one neuron, the activity was preferentially suppressed around this time. Neurons in Groups 5 and 6 had bimodal activity profiles. Neurons in Group $6(6 \%)$ were preferentially active during transitions between the swing and stance phases, whereas neurons in Group 5 (17\%) had the opposite tendency of reducing their firing during those transitions.

\section{Association between RF properties and patterns of activity modulation during locomotion}

The studied neurons had diverse RFs. The most commonly encountered RFs, found in $15 \%$ of the neurons, were small cutaneous fields confined to the ventral surface of the forepaw (Fig. $3 A, C)$. The rest of neurons had RFs of varying sizes and positions throughout the forelimb (Fig. 3B,D-F). Overall, a 58\% majority of neurons received their peripheral input from cutaneous mechanoreceptors, $29 \%$ of neurons received their input from mechanoreceptors innervating joints or deep tissues, and 13\% of neurons received mixed skin and deep inputs. Distal forelimb regions (i.e., those located on the wrist or paw) were more commonly included in the skin RFs than the proximal forelimb regions (Fig. 3G). In contrast, the deep RFs had a greater tendency to include proximal limb regions than distal ones (Fig. 3G). The mixed-submodality RFs included both distal and proximal forelimb regions (Fig. 3G). The great majority of neurons were excited by stimulation of their RF, whereas only five cells were inhibited.

Each of the six cell groups illustrated in Figure 8 included neurons with diverse RF properties. All groups had comparable ratios of cells with skin and deep RFs, showing that these groups had no preference for one or the other RF submodality. Preferences, however, were seen with regard to RF location on the limb. Neurons with proximal RFs restricted to the shoulder, upper arm, and forearm ("exclusively proximal" RFs) as a group during locomotion on the flat surface discharged intensively throughout all of the swing phase, with an average population peak at $\sim 20$ spikes/s, and were only half as active during midstance (Fig. 9A).

Neurons with RFs that included some proximal (upper arm and/or forearm) and some distal (wrist, paw) forelimb regions ("proximal+ distal" RFs) discharged more vigorously during the swing phase as well, but reached the peak of their activity only in the middle of this phase (Fig. 9B).

Neurons with RFs confined to the wrist and/or paw ("exclusively distal" RFs) were activated still later in the cycle, reaching the activity peak during transition from the swing to stance phases (Fig. 9C). In addition, these neurons were $\sim 50 \%$ more active at their peak than either of the more proximal groups.

Therefore, it appeared that, during the stride cycle, the activity of neurons with proximal RFs tended to lead the activity of neurons with more distal RFs. This observation was supported by the results of the analysis of distribution of distal versus proximal RFs among the six types of activity profiles shown in Figure 8. Namely, 

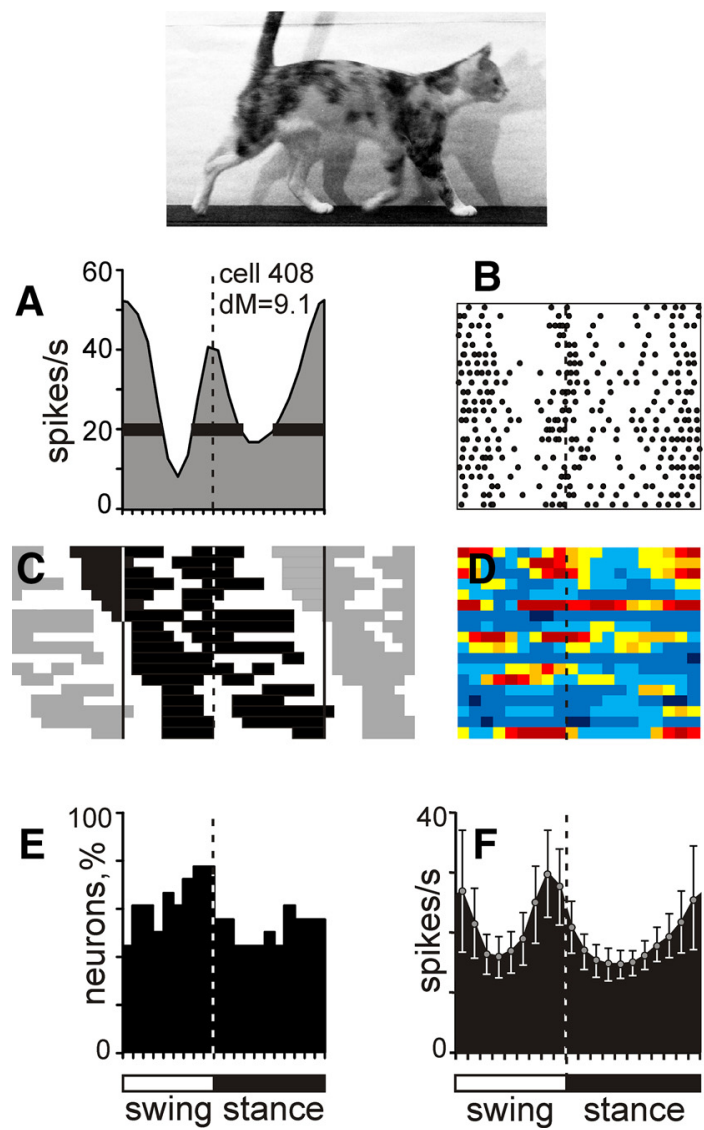

Figure 7. Population characteristics of two-PEF neurons. $\boldsymbol{A}, \boldsymbol{E}$, Example activity of a neuron during walking on the flat surface $(\boldsymbol{A}, \boldsymbol{B})$ and along the horizontal ladder $(\boldsymbol{G}, \boldsymbol{H})$ presented as histograms $(\boldsymbol{A}, \boldsymbol{G})$ and rasters $(\boldsymbol{B}, \boldsymbol{H} ; 22$ strides and 16 strides, respectively). In $\boldsymbol{A}, \boldsymbol{B}, \boldsymbol{G}$, and $\boldsymbol{H}$, designations are as in Figure 4 . $\boldsymbol{C}, \boldsymbol{I}$, Phase distribution of PEFs during walking on the flat surface $(\boldsymbol{C})$ and along the ladder $(\boldsymbol{I})$. The top row shows PEFs of the neuron, the activity of which is shown in $\boldsymbol{A}, \boldsymbol{B}, \boldsymbol{G}$, and $\boldsymbol{H}$. $\boldsymbol{E}, \boldsymbol{K}$, Proportion of active neurons (neurons in their PEF) in different phases of the step cycle. $\boldsymbol{F}, \boldsymbol{L}$, The mean discharge rate at different phases of the step cycle. Error bars show SEM.

neuronal group 2, which included cells most active when the foot was coming in contact with the ground, consisted almost exclusively from neurons with distal RFs ( $p<0.01, z$ test for proportions).

In contrast, Group 5, the group of two-peaked neurons active both in the midswing and midstance, was dominated by cells with RFs encompassing both distal and proximal limb.

Neurons that had cutaneous RFs restricted to the ventral surface of the forepaw presented a special opportunity to gauge how much stride-related activity patterns of neurons in areas 1 and 2 reflect the stride-related spike discharge patterns of the mechanoreceptors that innervate these neurons. The pattern of firing of cutaneous mechanoreceptors on the ventral forepaw during locomotion can be expected to be greatly dominated by the forepaw coming into contact with the ground during the stance phase of the stride and the time course of the force exerted by the foot on the ground during the stance phase (Fig. 10A). According to these considerations, neurons of areas 1 and 2 with cutaneous RFs on the ventral forepaw should start generating prominent spike discharges about $20 \mathrm{~ms}$ after the moment the foot touches the ground (given that the shortest transmission latency from cat's forepaw to middle layer cells in area $3 \mathrm{~b}$ is $\sim 15 \mathrm{~ms}$; Diamond, 1989) and behave as neurons of Group 3 (Fig. 8).

Twelve neurons isolated in this study had cutaneous RFs restricted to the ventral surface of the forepaw and their stride activity profiles are plotted in Figure $10 \mathrm{~B}$. The majority of cells $(n=8)$ had their activity centered on the moment of the foot coming in contact with the ground (the Group 2 type). Two other neurons were of the Group 6 type, firing preferentially around the time of the foot making contact with the ground and also breaking contact. One cell fired throughout the stride cycle, but more in the swing phase than in the stance phase, placing it in the Group 1 category. Only one neuron had its activity raised during the stance phase as the Group 3 type (neuron 433 shown on top left), resembling at least to some degree the expected pattern of its peripheral drive.

The most striking feature of the behavior of these cells is that all 12 began to increase their firing $50-150 \mathrm{~ms}$ before the physical contact of the foot with the ground even though during this time-according to their RFs - these cells should not be receiving any significant afferent input. The other striking feature is that all cells, except for a single Group 3 cell, reached the peak of their firing very near the moment of the foot touching the ground. Four cells had their firing peak just before the physical contact, five cells had their peak just after the physical contact and before the afferent input could reach SI, and only two cells had their peaks 25-30 ms after the physical contact. None of these 11 cells showed evidence of any major surge in spike firing that could be attributed to activation of mechanoreceptors by the foot touching the ground.

Overall, Figure 10C suggests that activity of neurons with RFs restricted to the ventral surface of the forepaw was driven during locomotion to a large extent by anticipation of the foot coming in contact with the ground, as opposed to reacting to such a contact.

Association between axonal conduction velocity and patterns of activity modulation during locomotion

Twenty-four cells (29\%) responded antidromically to electrical stimulation of the pyramidal tract. The latencies of responses 

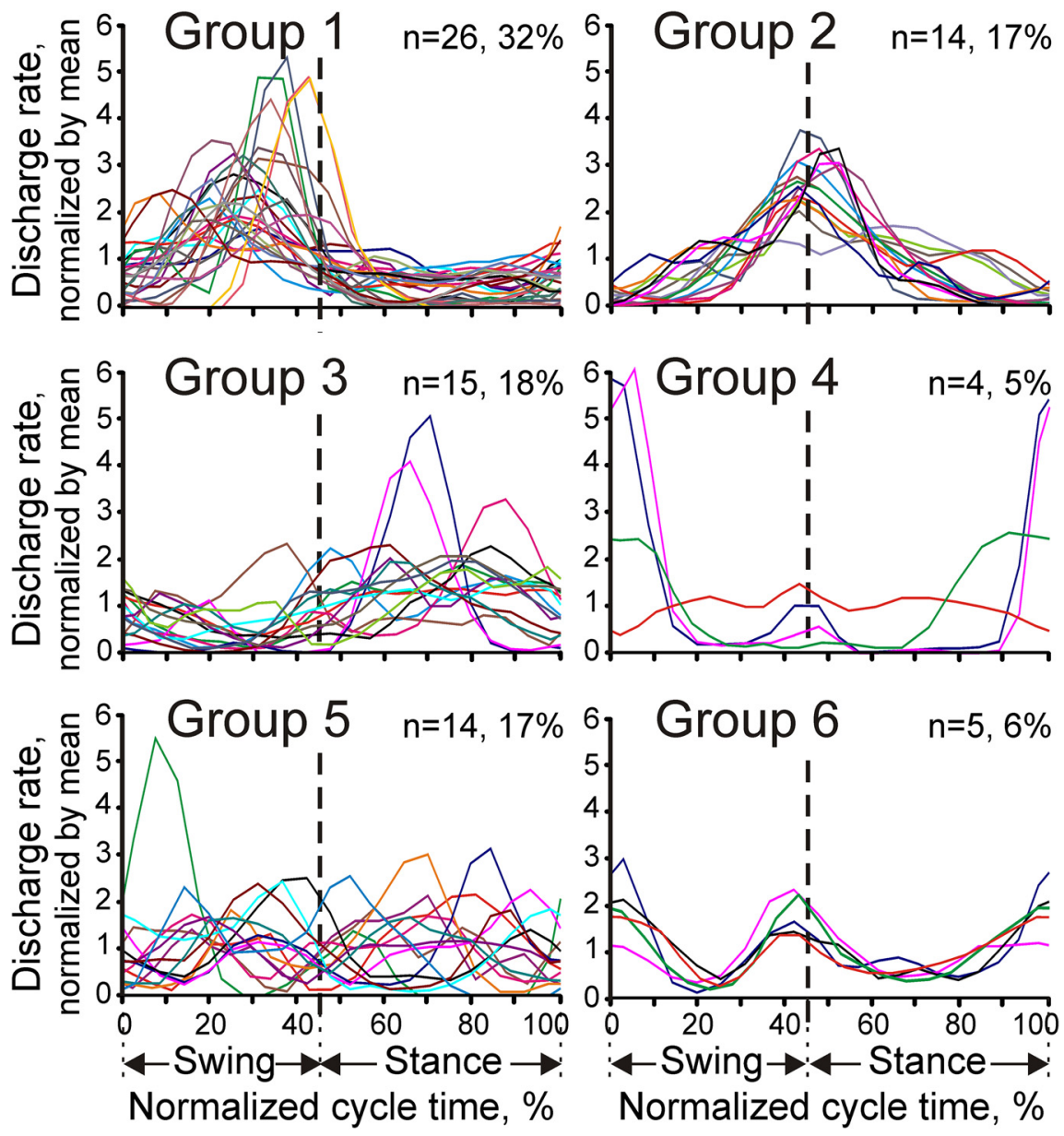

Figure 8. Six groups of stride-related activity patterns. Each plot shows superimposed the stride activity profiles of all studied cells belonging to a particular group.

varied in the range of $0.8-3.0 \mathrm{~ms}$. Estimated conduction velocities were between 17 and $60 \mathrm{~m} / \mathrm{s}$. Approximately $1 / 2$ of neurons $(13 / 24)$ responded at $2.0 \mathrm{~ms}$ or faster, conducting at $25 \mathrm{~m} / \mathrm{s}$ or faster, and thus were classified as "fast-conducting" PTNs, the other half were "slow-conducting" PTNs (Brookhart and Morris, 1948; Bishop et al., 1953; Takahashi, 1965). Sixteen of 26 penetrations $(62 \%)$ yielded at least one PTN, and these tracks were distributed throughout the studied cortical area.

PTNs with different axonal conduction velocities were different in phasing of their population activity regardless of their RFs. Although PEFs of individual fast- and slow-conducting PTNs were distributed over the stride cycle (Figs. 11A1-A3,B1-B3), the average population activity of fast-conducting PTNs peaked during transition from the swing to the stance phases (Fig. 11A3,A4), reaching $\sim 50$ spikes/s. In contrast, the activity of slowconducting PTNs peaked earlier in the cycle, during the midswing phase, albeit only reaching $\sim 35$ spikes/s, $\sim 50 \%$ less than the peak activity of fast-conducting PTN group. Therefore, the activity of the slow-conducting PTN group led that of the fastconducting PTN group.

\section{Changes to the activity evoked by necessity to step accurately} on the ladder

The activity of all but one neuron recorded during walking on the flat surface was also recorded when cats walked along the horizontal ladder. Discharges of the overwhelming majority of the neurons $(74 / 81,91 \%)$ were different between the two walking tasks. Typical examples are shown in Figures 4 and $7, A, B, G$, and $H$, and are described in the corresponding text.

The average discharge rate was different in $54 \%(44 / 81)$ of neurons. From these, half of cells $(22 / 81,27 \%)$ were more active during walking on the ladder than on the flat surface, on average by $73 \%$, whereas the other half were less active, on average by $32 \%$ (Fig. 5B). Neurons with RFs on the wrist and/or paw had a tendency to decrease the discharge rate, whereas those with RFs on the arm or forearm tended to increase it. Across all groups, fast-conducting PTNs typically decreased activity during walking on the ladder, whereas slow-conducting PTNs typically increased it ( $p>0.05, \chi^{2}$ test). Because changes in the activity of different neurons were often of opposite directions, the average discharge rate of the whole studied population was similar between the walking tasks. $(17.5 \pm 1.5$ vs $16.6 \pm$ 1.4 spikes/s, $p>0.05, t$ test $)$.

The stride-to-stride VMR was $1.42 \pm$ 0.74 (mean \pm SD), which was statistically significantly smaller than during walking on the flat surface ( $p=0.044, t$ test). Only five individual neurons, however, showed statistically significant differences in the variability of their mean discharge rates between the two tasks, and three of them were recorded sequentially along the same microelectrode penetration.

During walking along the ladder, the activity of all cells was modulated with relation to the stride. The same two major forms of modulation as during walking on the flat surface were observed: one PEF was seen in $72 \%$ of neurons (58/81) and two PEFs were found in $26 \%$ $(21 / 81)$ of cells. Two additional cells had three PEFs. Proportions of cells with different number of PEFs were similar to those seen during walking on the flat surface $(p>0.05, t$ test). The $d M$, however, was different in $46 \%$ (37/81) of neurons. During walking along the ladder, it was higher in 23 cells by $40 \pm 21 \%$ and lower in 14 by $27 \pm 13 \%$ (mean \pm SD; Fig. 5C). Two-PEF neurons nearly always increased the depth of their frequency modulation, and the average $d M$ for their group was much higher during walking along the ladder than on the flat surface (16.4 \pm 1.7 vs $10.1 \pm 0.6, p=0.003)$. Groups of neurons with different RF properties (e.g., proximal vs distal, skin vs deep) and PTNs with different axonal conduction velocities had approximately similar proportions of cells increasing and decreasing $d M$ upon transition from the flat surface to ladder.

The duration of the PEF was different between the tasks in $15 \%(12 / 81)$ of neurons: during walking along the ladder, it was longer in eight and shorter in five cells by $25-50 \%$ of the cycle. Neurons with RFs confined to the wrist and paw were different from cells with exclusively proximal RFs in their strong preference not to change duration of the PEF ( $p<0.05, z$ test).

Neurons typically had the same number of PEFs during both locomotor tasks $(62 / 81,77 \%$ of cells). However, $17 \%(11 / 63)$ of neurons that had a one-PEF pattern during flat surface walking changed to two PEFs during walking along the ladder. Con- 

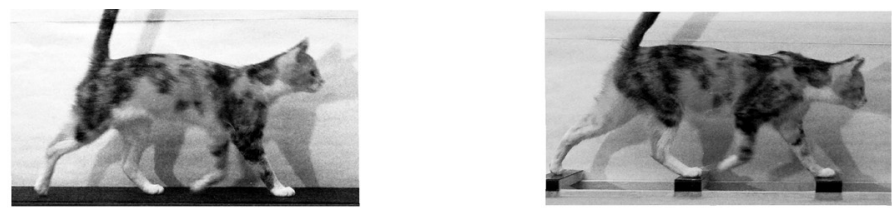

Shoulder/arm/forearm ONLY

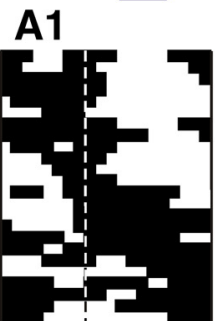

$$
\text { A2 }
$$
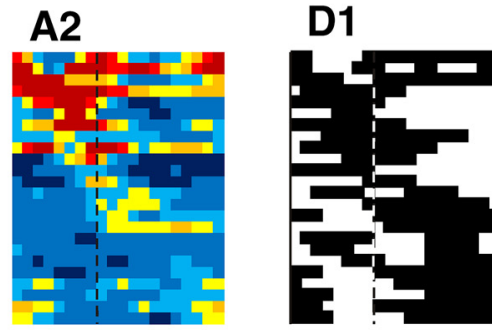

D2
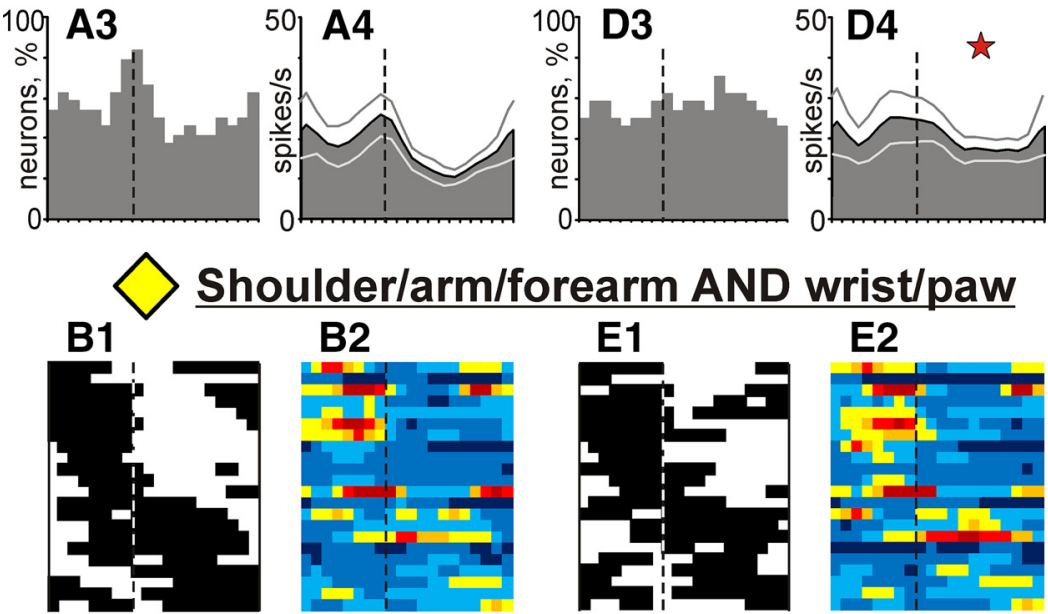

Shoulder/arm/forearm AND wrist/paw
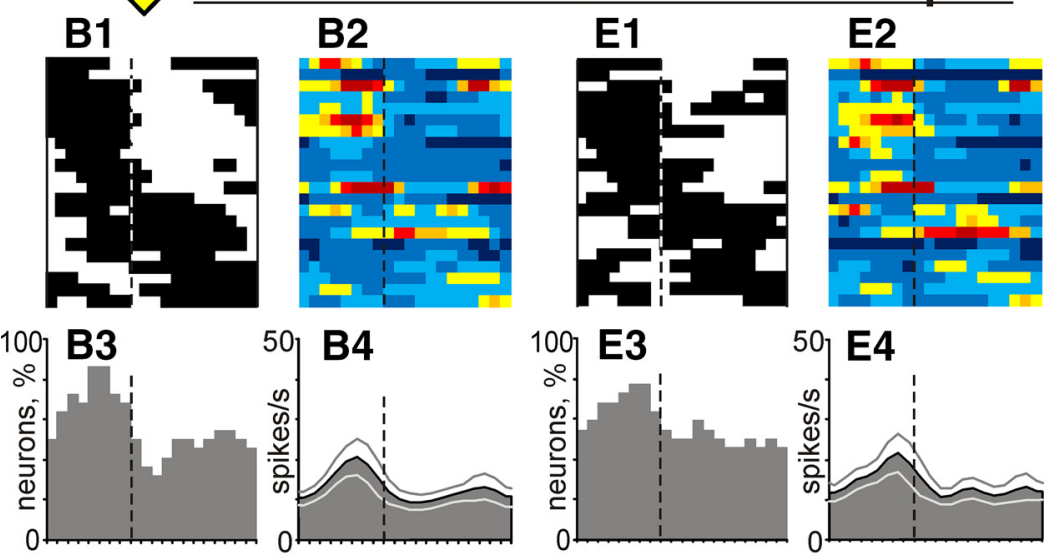

Wrist/paw ONLY

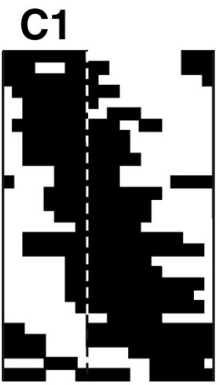

C2
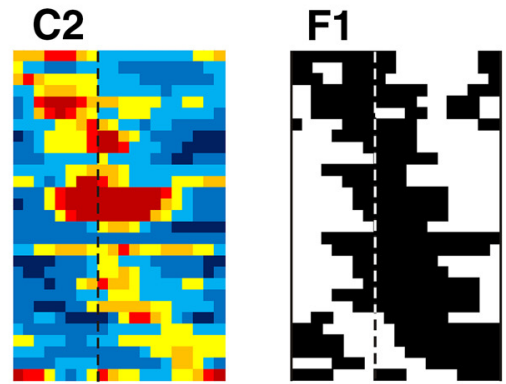

F2
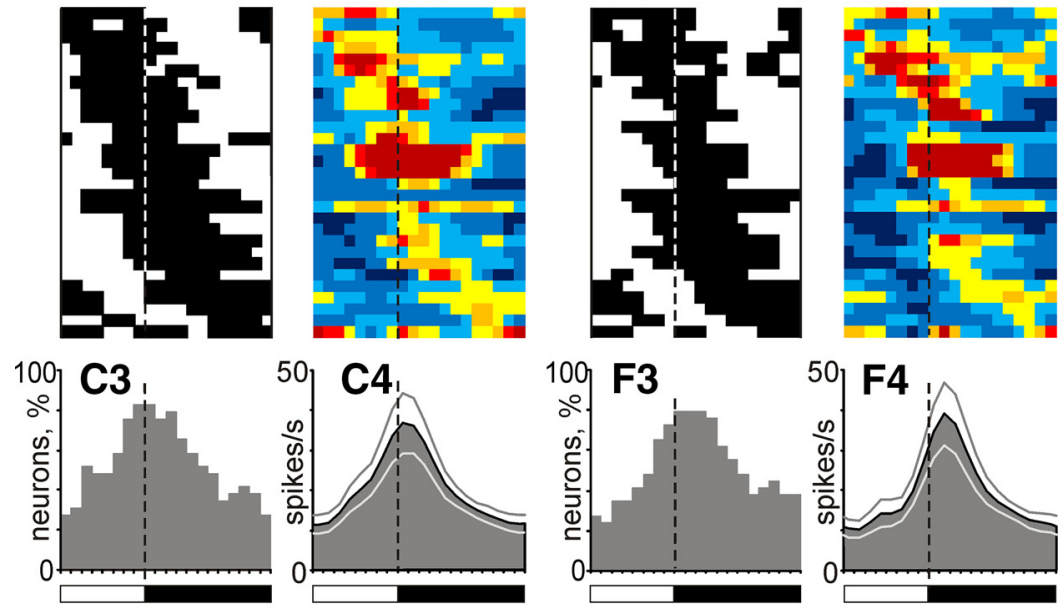

swing stance swing stance

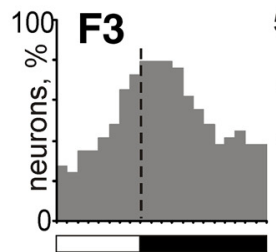

swing stance

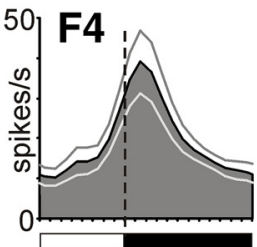

swing stance

$\begin{array}{lllllll}0-1 & 1-10 & 10-20 & 20-30 & 30-40 & 40-50 & 50+\mathrm{imp} / \mathrm{s}\end{array}$



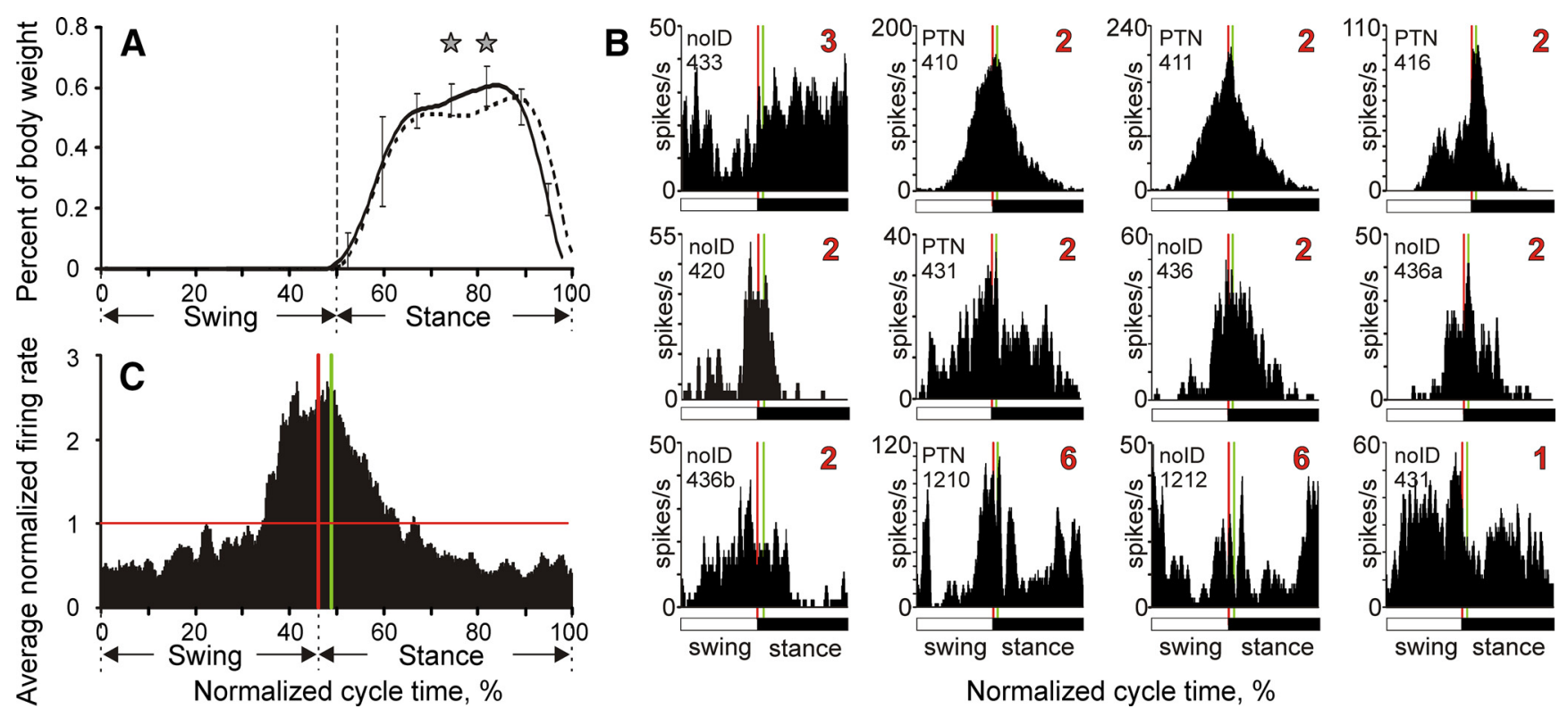

Figure 10. Stride-related activity of 12 neurons with cutaneous RFs restricted to the ventral side of the forepaw. $\boldsymbol{A}$, Vertical ground reaction forces during walking on the flat surface (solid line) and horizontal ladder (interrupted line). SDs were similar between the tasks and for clarity are shown only for flat surface walking (error bars). Stars indicate statistically significant differences between the walking tasks ( $p<0.05, t$ test). $\boldsymbol{B}$, Activity profiles of the 12 cells during locomotion on the flat surface. Vertical lines indicate the moment of the foot making contact with the ground (red) and 15 ms later (green). C, Average activity profile of the 12 cells, each normalized by its mean firing rate during flat surface walking.

\section{Discussion}

We found that, during walking on a flat surface, the firing rates of all of the cells that were isolated in microelectrode penetrations through the rostral bank of the ansate sulcus and possessed RFs on the contralateral forelimb were periodically modulated as a function of the phase of the stride. In addition, $44 \%$ of cells increased their mean firing rate during locomotion, whereas $22 \%$ of cells decreased it compared with their mean firing rate while standing. Overall, the mean firing rate of this neurons' sample was 14 spikes/s during standing and 17 spikes/s during walking. These numbers are comparable to average firing rates of neurons in areas 1-2 reported by Fitzsimmons and colleagues (2009) for bipedal treadmill locomotion of macaque monkeys.

Although all cells in the study were affected by walking, they varied greatly in how they were affected. Individual cells were activated at different phases of the step cycle and 95\% could be sorted into six groups based on the timing of their spike firing relative to the stride cycle (Fig. 8). Some cells fired preferentially during the swing phase, other cells fired during the stance phase, and still other cells fired at the transition phases from swing to stance, from stance to swing, or both. The specific pattern of firing correlated with the RF location on the limb. Neurons with proximal RFs (upper arm or shoulder) tended to fire at peak rates in the middle of the swing (Group 1). They appeared to be analogous to those neurons of primates in which activity profiles during arm reaching movements were similar to that of the velocity of reaching: peaking between the onset of the reach and arrival at the target (Gardner et al., 2007); these reaching movements are largely performed by proximal muscles, especially those of the shoulder and elbow. In contrast, neurons with RFs on the distal limb (wrist/paw) typically showed peak firing at the transition between swing and stance phases immediately prior and right after the paw contacted the floor at the beginning of stance (Group 2). These neurons, along with neurons of Groups 4 and 6, which were activated at peak rates at the breaking (Group 4) or making and breaking (Group 6) of paw contact with the floor, might be similar in function to the primate's neurons that fire at hand contact before grasping and/or release of objects held in the hand (Gardner et al., 2007). Neurons in Group 3 fired most intensively during stance and thus might have signaled alterations in the disposition of the animal's weight during that phase. Within each group, cells differed in the timing of their peak firing. As a result, each moment in the stride cycle was characterized by a unique spatial pattern of activity in the areas 1-2 neuron population. Such instantaneous spatial patterns of activity in areas 1-2 can therefore be used to infer the state of ongoing locomotion.

The pattern of firing activity was also distinct between groups of fast- and slow-conducting PTNs regardless of their RFs (Fig. 11). This suggests that these cortical efferent neurons have distinct roles in control of walking, as was previously also suggested for fast- and slow-conducting PTNs of the motor cortex (Stout and Beloozerova, 2013). Fast- and slow-conducting PTNs differ in their connections to the spinal cord, such that fast-conducting PTNs preferentially influence distal muscle-related networks, whereas slow-conducting PTNs influence both proximal and distal muscle-related networks (Brookhart and Morris, 1948). Correspondingly, population activity of fast-conducting PTNs peaked at the transition from swing to stance when control of the distal limb was most critical, whereas the slow-conducting PTN group fire most actively during midswing, where we have shown previously that the length of the limb is stabilized actively (Klishko et al., 2014).

The patterns of spike discharge activity generated by the population of neurons during walking on a flat surface or on a horizontal ladder were qualitatively similar. However, many individual neurons exhibited statistically significant quantitative differences in their mean firing rate and/or characteristics of stride-related activity modulation between these two locomotor tasks (Fig. $5 B, C$ ), just as there were quantitative differences in the cat's manner of walking on a flat surface versus a ladder, which, in addition to a dramatic difference in the variability of stride 
lengths, included distinctions in the posture of the neck and head (Fig. 1A,B), flexion of distal joints, and few other variables (all analyzed in detail in Beloozerova et al., 2010). These differences suggest that spatiotemporal activity patterns generated in areas 1-2 during locomotion might carry detailed information on the fine status of the skeletomuscular locomotor apparatus on a moment-by-moment basis. Indeed, using linear decoders, Fitzsimmons et al. (2009) were able to extract information about positions and angles of the hip, knee, and ankle joints; leg muscle contractions; foot contact with the ground; step length; and walking speed from spike-firing patterns of multiple neurons recorded simultaneously in areas 1-2 of monkeys engaged in bipedal walking on a treadmill. The fact that a dramatic decrease in the variability of the stride length during accurate stepping on the ladder compared with unconstrained walking (Beloozerova et al., 2010) is accompanied by a decrease in the variability of neuronal discharges during this cortex-controlled task, which we found here, further supports the above suggestion.

A large body of literature shows that SI activity in behaving subjects does not simply reflect the spatiotemporal patterns of activation of mechanoreceptors, but is shaped by other central factors such as sensory gating by anticipatory or efference copy inputs from the motor system. In this study, the influence of such factors on SI activity during locomotion could be ascertained among those sampled neurons that had cutaneous RFs on the ventral surface of the contralateral forepaw. Afferent drive to these neurons should have been initiated and terminated at each walking step by the forepaw coming in contact and leaving the ground. However, 11 of 12 such cells increased their firing 50-150 ms before the physical contact of the forepaw with the ground (Fig. 10B), during which time they were not expected to receive any significant peripheral drive. Half of all the spikes discharged by these cells as a group during a stride cycle occurred before the foot touching the ground, at least for the range of walking speeds that we have analyzed (Fig. 10C). Such anticipatory behavior suggests that these cells acted in a predictive mode (Bubic et al., 2010).

Anticipatory activity or sensory response modulation on a similar timescale was commonly observed in primate areas 1-2 before onset of a haptic task or even before simple voluntary wrist or elbow movements (Soso and Fetz, 1980; Fromm and Evarts, 1982; Nelson, 1987; Koch and Fuster, 1989; Lebedev et al., 1994; Weber et al., 2011; London and Miller, 2013). Such anticipatory cortical activity is generally thought to be driven by efference copy inputs from the motor system, intended to facilitate the processing of the expected sensory and motor events. Anticipatory activity can also be evoked in SI without any motor action, however, by just expecting to receive a tactile stimulus (Carlsson Other designations are as in Figure 6.

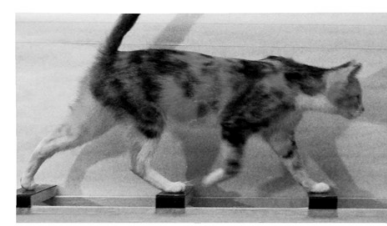

Fast PTNs
A2
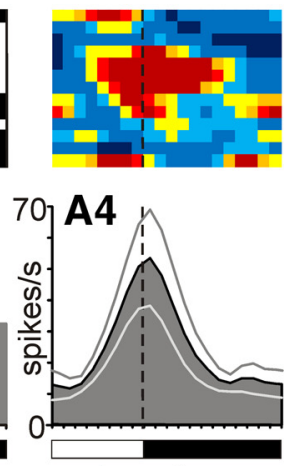

swing stance
C1
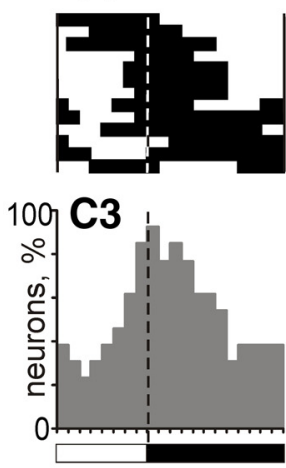

swing stance
C2
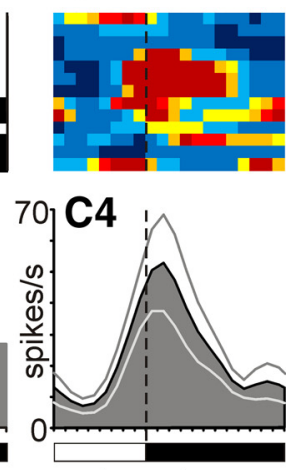

swing stance

\section{Slow PTNs}

B2

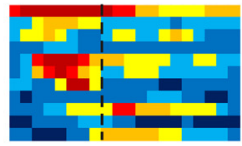

70] B4

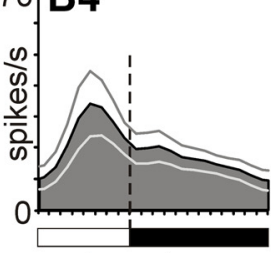

swing stance
D1
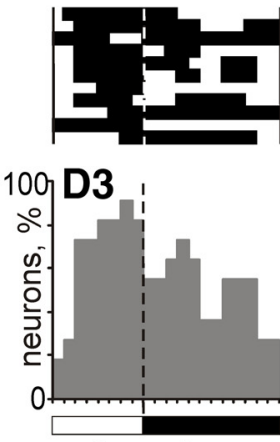

swing stance
D2

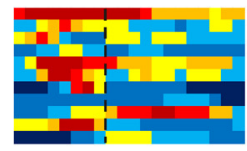

70. D4

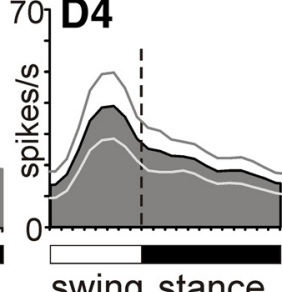

swing stance

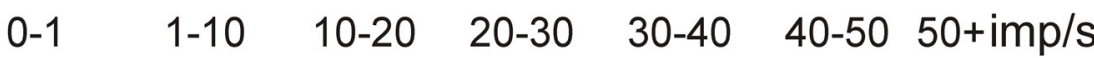

Figure 11. Fast- and slow-conducting PTNs tend to discharge during different phases of the stride. $A, C$, Activity of fastconducting PTNs during walking on the flat surface $(\boldsymbol{A})$ and along the ladder (C). $\boldsymbol{B}, \boldsymbol{D}$, Activity of slow-conducting PTNs neurons.

et al., 2000). In this case, the anticipatory activity in SI is triggered, for example, by a visual cue that must be transmitted to SI by a top-down mechanism engaging higher-level sensory cortical areas. Therefore, it is possible that a significant portion of differences in firing activity of individual neurons between flat surface and ladder walking (Fig. $5 B, C$ ) arose from differences in visual cues used for guiding stepping during these tasks (Rivers et al., 2014).

However, unlike other studies in which anticipatory activity in SI was observed while the subject was in a relaxed state, expecting a tactile stimulus, or getting ready for a motor act, in this study, we observed anticipatory activity while the cat was already in an active state-walking — with neurons in areas 1-2 firing spikes on each stride cycle ahead of the movement-generated stimulation of their RFs. In this situation, the precontact anticipatory activity may reflect the rhythm of walking that is generated in the spinal cord (Graham Brown, 1911; Grillner and Zangger, 1979; McCrea and Rybak, 2008) and the postcontact activity may reflect infor- 
mation on the action that has been accomplished. In addition to the motor system and higher-level sensory areas, the anticipatory spike firing in areas 1-2 can be also driven locally by other active neurons within the areas in which RFs are stimulated earlier in the stride cycle. For example, neurons with proximal RFs may drive those with distal RFs (Figs. 9, 10) and slow-conducting PTNs may drive fast-conduction ones (Fig. 11). Therefore, given that locomotion is a regularly practiced behavioral activity in which limbs cycle through a highly reproducible temporal sequence of muscle contractions and joint movements, one can expect that in an SI neuronal population modulated by walking, those neurons that are engaged (by virtue of their RF properties) earlier in a stride cycle will have well developed lateral excitatory connections onto other neurons that are engaged a little later in the same cycle (Drew and Abbott, 2006). Additional experiments, however, are necessary to determine specific sources of the predictive activity in areas 1-2 during locomotion.

Regardless of the source, it is interesting that the peak of anticipatory activity among our studied neurons closely matches the timing of the actual physical contact of the forepaw with the ground (Fig. 10C) rather than the timing of the arrival of the contact-evoked afferent input to those neurons. This timing suggests that areas 1-2 signaled a sensory event (i.e., a foot contact) exactly when it occurred by predicting it rather than signaling it "after the fact" by responding to the event-evoked afferent input. Such a predictive manner of sensory event representation appears to be common to sensory perception in general and is referred to as "perceiving-the-present" (Changizi et al., 2008). However, this present study is the first one to reveal neuronal correlates of the predictive sensation during locomotion.

Numerous studies have shown that active limb movements suppress transmission to SI of spike discharges evoked in somatosensory afferents by peripheral stimulation even if that stimulation was unrelated to the movement (Chapin and Woodward, 1981, 1982b; Jiang et al., 1991; Shin et al., 1994; Seki and Fetz, 2012). Such nonspecific somatosensory gating takes place all along the somatosensory pathways, including the dorsal column nuclei (Ghez and Pisa, 1972; Coulter, 1974; Chapman et al., 1988) and ventrobasal thalamus (Coquery, 1978; Shin et al., 1993). We see possible evidence of such sensory gating in our study in that, in the 10 cells of the 12 that had cutaneous RFs on the ventral forepaw, the first half of the stance period (during which the contact-activated afferent input from the foot should be quickly rising) was associated with a prominent decline-rather than increase - of spike firing. However, such a decline in firing might also be due to a more selective integration of internally generated prediction with the actual sensory information (Chapin and Woodward, 1982a; Bays et al., 2006; London and Miller, 2013). Theoretically, such integration might emphasize "error signals" - deviations of the sensory signal from predicted-so that neural activity in SI does not represent all the afferent somatosensory information, but only the part that is not predicted accurately by the internal model (Rao and Ballard, 1999; Alink et al., 2010; den Ouden et al., 2010). Alternatively, integration of prediction with the afferent information might be used to produce the representation of sensory events that is more accurate than possible from either source alone, resulting in lower average activation and a higher signal-to-noise ratio (Murray et al., 2004; Vaziri et al., 2006).

To conclude, in this study, we found that the activity of neurons in areas 1-2, the high subdivisions of SI, prominently reflects highly predictable somatosensory events, such as those generated by locomotion, both shortly before and after these events take place, and that this activity differs between unrestrained locomotion and accurate target stepping.

\section{References}

Alink A, Schwiedrzik CM, Kohler A, Singer W, Muckli L (2010) Stimulus predictability reduces responses in primary visual cortex. J Neurosci 30: 2960-2966. CrossRef Medline

Andujar JE, Drew T (2007) Organization of the projections from the posterior parietal cortex to the rostral and caudal regions of the motor cortex of the cat. J Comp Neurol 504:17-41. CrossRef Medline

Batshelet E (1981) Circular statistics in biology. New York: Academic.

Bays PM, Flanagan JR, Wolpert DM (2006) Attenuation of self-generated tactile sensations is predictive, not postdictive. PLoS Biol 4:e28. CrossRef Medline

Beloozerova IN, Sirota MG (1993) The role of the motor cortex in the control of accuracy of locomotor movements in the cat. J Physiol 461:1-25. CrossRef Medline

Beloozerova IN, Sirota MG (2003) Integration of motor and visual information in parietal area 5 during locomotion. J Neurophysiol 90:961-971. CrossRef Medline

Beloozerova IN, Sirota MG, Swadlow HA (2003a) Activity of different classes of neurons of the motor cortex during locomotion. J Neurosci 23:1087-1097. Medline

Beloozerova IN, Farrell BJ, Sirota MG, Prilutsky BI (2010) Differences in movement mechanics, electromyographic, and motor cortex activity between accurate and non-accurate stepping. J Neurophysiol 103:22852300. CrossRef Medline

Bishop PO, Jeremy D, Lance JW (1953) Properties of pyramidal tract. J Physiol 5:537-549. Medline

Bishop PO, Burke W, Davis R (1962) The identification of single units in central visual pathways. J Physiol 162:409-431. CrossRef Medline

Brookhart JM, Morris RE (1948) Antidromic potential recordings from the bulbar pyramid of the cat. J Neurophysiol 11:387-398. Medline

Bubic A, von Cramon DY, Schubotz RI (2010) Prediction, cognition and the brain. Front Hum Neurosci 4:25. Medline

Carlsson K, Petrovic P, Skare S, Petersson KM, Ingvar M (2000) Tickling expectations: neural processing in anticipation of a sensory stimulus. J Cogn Neurosci 12:691-703. Medline

Chambers WW, Liu CN (1957) Corticospinal tract of the cat: an attempt to correlate the pattern of degeneration with deficits in reflex activity following neocortical lesions. J Comp Neurol 108:23-55. CrossRef Medline

Changizi MA, Hsieh A, Nijhawan R, Kanai R, Shimojo S (2008) Perceiving-thepresent and a general theory of illusions of projected size, projected speed, luminance contrast and distance. Cogn Sci 32:459-503. CrossRef Medline

Chapin JK, Woodward DJ (1981) Modulation of sensory responsiveness of single somatosensory cortical cells during movement and arousal behaviors. Exp Neurol 72:164-178. CrossRef Medline

Chapin JK, Woodward DJ (1982a) Somatic sensory transmission to the cortex during movement: gating of single cell responses to touch. Exp Neurol 78:654-669. CrossRef Medline

Chapin JK, Woodward DJ (1982b) Somatic sensory transmission to the cortex during movement: gating of single cell responses to touch. Exp Neurol 78:670-684. CrossRef Medline

Chapman CE, Jiang W, Lamarre Y (1988) Modulation of lemniscal input during conditioned arm movements in monkeys. Exp Brain Res 72:316334. Medline

Clascá F, Llamas A, Reinoso-Suárez F (2000) Cortical connections of the insular and adjacent parieto-temporal fields in the cat. Cereb Cortex 10: 371-399. CrossRef Medline

Coquery JM (1978) Role of active movement in control of afferent input from skin in cat and man. In: Active touch (Gordon G, ed), pp 161-170. Oxford: Pergamon.

Coulter JD (1974) Sensory transmission through lemniscal pathway during voluntary movement in the cat. J Neurophysiol 37:831-845. Medline

den Ouden HE, Daunizeau J, Roiser J, Friston KJ, Stephan KE (2010) Striatal prediction error modulates cortical coupling. J Neurosci 30:32103219. CrossRef Medline

Diamond ME (1989) Organization of somatic sensory cortex: the detection of discrete topographic units and evidence for their integrative function. $\mathrm{PhD}$ dissertation, University of North Carolina at Chapel Hill.

Drew PJ, Abbott LF (2006) Extending the effects of spike-timing-dependent 
plasticity to behaving timescales. Proc Natl Acad Sci U S A 103:88768881. CrossRef Medline

Drew T, Doucet S (1991) Application of circular statistics to the study of neuronal discharge during locomotion. J Neurosci Methods 38:171-181. CrossRef Medline

Dykes RW, Rasmusson DD, Hoeltzell PB (1980) Organization of primary somatosensory cortex in the cat. J Neurophysiol 43:1527-1546. Medline

Efron B, Tibshirani RJ (1993) An introduction to the bootstrap. New York: Chapman and Hall.

Favorov OV, Nilaweera WU, Miasnikov AA, Beloozerova IN (2010) Profound activity of somatosensory responsive neurons in high subdivisions of SI cortex during simple locomotion. Program No. 178.15. 2010 Neuroscience Meeting Planner. San Diego: Society for Neuroscience.

Fee MS, Mitra PP, Kleinfeld D (1997) Central versus peripheral determinants of patterned spike activity in rat vibrissa cortex during whisking. J Neurophysiol 78:1144-1149. Medline

Felleman DJ, Van Essen DC (1991) Distributed hierarchical processing in the primate cerebral cortex. Cereb Cortex 1:1-47. Medline

Fisher NI (1993) Statistical analysis of circular data. Cambridge, MA: Cambridge University.

Fitzsimmons NA, Lebedev MA, Peikon ID, Nicolelis MA (2009) Extracting kinematic parameters for monkey bipedal walking from cortical neuronal ensemble activity. Front Integr Neurosci 3:3. Medline

Friel KM, Drew T, Martin JH (2007) Differential activity-dependent development of corticospinal control of movement and final limb position during visually guided locomotion. J Neurophysiol 97:3396-3406. CrossRef Medline

Fromm C, Evarts EV (1982) Pyramidal tract neurons in somatosensory cortex: central and peripheral inputs during voluntary movement. Brain Res 238:186-191. CrossRef Medline

Fuller JH, Schlag JD (1976) Determination of antidromic excitation by the collision test: problems of interpretation. Brain Res 112:283-298. Medline

Gardner EP, Ro JY, Babu KS, Ghosh S (2007) Neurophysiology of prehension. II. Response diversity in primary somatosensory (S-I) and motor (M-I) cortices. J Neurophysiol 97:1656-1670. Medline

Ghez C, Pisa M (1972) Inhibition of afferent transmission in cuneate nucleus during voluntary movement in the cat. Brain Res 40:145-155. CrossRef Medline

Ghosh S (1997a) Cytoarchitecture of sensorimotor areas in the cat cerebral cortex. J Comp Neurol 388:354-370. CrossRef Medline

Graham Brown T (1911) The intrinsic factors in the act of progression in the mammal. Proc Royal Soc Lond (B) 84:308-319. CrossRef

Grillner S, Zangger P (1979) On the central generation of locomotion in the low spinal cat. Exp Brain Res 34:241-261. Medline

Hassler R, Muhs-Clement K (1964) Architectonic construction of the sensomotor and parietal cortex in the cat [article in German]. J Hirnforsch 1964;7:377-420.

Hildebrand M (1965) Symmetrical gaits of horses. Science 150:701-708. CrossRef Medline

Ito S, Craig AD (2003) Vagal input to lateral area 3a in cat cortex. J Neurophysiol 90:143-154. CrossRef Medline

Iwamura Y (1998) Hierarchical somatosensory processing. Curr Opin Neurobiol 8:522-528. CrossRef Medline

Jiang W, Chapman CE, Lamarre Y (1991) Modulation of the cutaneous responsiveness of neurons in the primary somatosensory cortex during conditioned arm movements in the monkey. Exp Brain Res 84:342-354. Medline

Kleinfeld D, Deschênes M (2011) Neuronal basis for object location in the vibrissa scanning sensorimotor system. Neuron 72:455-468. CrossRef Medline

Klishko AN, Farrell BJ, Beloozerova IN, Latash ML, Prilutsky BI (2014) Stabilization of cat paw trajectory during locomotion. J Neurophysiol 112: 1376-1391. CrossRef Medline

Koch KW, Fuster JM (1989) Unit activity in monkey parietal cortex related to haptic perception and temporary memory. Exp Brain Res 76:292-306. Medline

Lebedev MA, Denton JM, Nelson RJ (1994) Vibration-entrained and premovement activity in monkey primary somatosensory cortex. J Neurophysiol 72:1654-1673. Medline

Leclerc SS, Avendaño C, Dykes RW, Waters RS, Salimi I (1994) Reevaluation of area $3 \mathrm{~b}$ in the cat based on architectonic and electrophysiological studies: regional variability with functional and anatomical consistencies. J Comp Neurol 341:357-374. CrossRef Medline

Liddell EGT, Phillips CG (1944) Pyramidal section in the cat. Brain 67:1-9. CrossRef
London BM, Miller LE (2013) Responses of somatosensory area 2 neurons to actively and passively generated limb movements. J Neurophysiol 109: 1505-1513. CrossRef Medline

Marigold DS, Patla AE (2008) Visual information from the lower visual field is important for walking across multi-surface terrain. Exp Brain Res 188: 23-31. CrossRef Medline

McCrea DA, Rybak IA (2008) Organization of mammalian locomotor rhythm and pattern generation. Brain Res Rev 57:134-146. CrossRef Medline

McKenna TM, Whitsel BL, Dreyer DA, Metz CB (1981) Organization of cat anterior parietal cortex: relations among cytoarchitecture, single neuron functional properties, and interhemispheric connectivity. J Neurophysiol 45:667-697. Medline

Metz GA, Whishaw IQ (2002) Cortical and subcortical lesions impair skilled walking in the ladder rung walking test: a new task to evaluate foreand hindlimb stepping, placing, and co-ordination. J Neurosci Methods 115:169-179. CrossRef Medline

Murray SO, Schrater P, Kersten D (2004) Perceptual grouping and the interactions between visual cortical areas. Neural Netw 17:695-705. CrossRef Medline

Nelson RJ (1987) Activity of monkey primary somatosensory cortical neurons changes prior to active movement. Brain Res 406:402-407. CrossRef Medline

Prilutsky BI, Sirota MG, Gregor RJ, Beloozerova IN (2005) Quantification of motor cortex activity and full-body biomechanics during unconstrained locomotion. J Neurophysiol 94:2959-2969. CrossRef Medline

Pryor K (1975) Lads before the wind. New York: Harper and Row.

Rao RP, Ballard DH (1999) Predictive coding in the visual cortex: a functional interpretation of some extra-classical receptive-field effects. Nat Neurosci 2:79-87. CrossRef Medline

Rivers TJ, Sirota MG, Guttentag AI, Ogorodnikov DA, Shah NA, Beloozerova IN (2014) Gaze shifts and fixations dominate gaze behavior of walking cats. Neuroscience 275:477-499. CrossRef Medline

Seki K, Fetz EE (2012) Gating of sensory input at spinal and cortical levels during preparation and execution of voluntary movement. J Neurosci 32:890-902. CrossRef Medline

Sherk H, Fowler GA (2001) Neural analysis of visual information during locomotion. Prog Brain Res 134:247-264. CrossRef Medline

Shin HC, Park HJ, Chapin JK (1993) Differential phasic modulation of short and long latency afferent sensory transmission to single neurons in the ventroposterolateral thalamus in behaving rats. Neurosci Res 17:117125. CrossRef Medline

Shin HC, Park HJ, Chapin JK (1994) Differential phasic modulation of short and long latency afferent sensory transmission to single neurons in the primary somatosensory cortex in behaving rats. Neurosci Res 19:419 425. CrossRef Medline

Sirota MG, Swadlow HA, Beloozerova IN (2005) Three channels of corticothalamic communication during locomotion. J Neurosci 25:5915-5925. CrossRef Medline

Skinner BF (1938) The behavior of organisms. New York: AppletonCentury-Crofts.

Soso MJ, Fetz EE (1980) Responses of identified cells in postcentral cortex of awake monkeys during comparable active and passive joint movements. J Neurophysiol 43:1090-1110. Medline

Stout EE, Beloozerova IN (2013) Differential responses of fast- and slowconducting pyramidal tract neurons to changes in accuracy demands during locomotion. J Physiol 591:2647-2666. CrossRef Medline

Takahashi K (1965) Slow and fast groups of pyramidal tract cells and their respective membrane properties. J Neurophysiol 28:908-924. Medline

Trendelenburg W (1911) Untersuchungen über reizlose vorübergehende Aussaltung am Zentralnervensystem. III. Die extermitaten Region der Grosshirninde. Pflügers Archiv 137:515-544.

Vaziri S, Diedrichsen J, Shadmehr R (2006) Why does the brain predict sensory consequences of oculomotor commands? Optimal integration of the predicted and the actual sensory feedback. J Neurosci 26:4188-4197. CrossRef Medline

Weber DJ, London BM, Hokanson JA, Ayers CA, Gaunt RA, Torres RR, Zaaimi B, Miller LE (2011) Limb-state information encoded by peripheral and central somatosensory neurons: implications for an afferent interface. IEEE Trans Neural Syst Rehabil Eng 19:501-513. CrossRef Medline 